Research Paper

\title{
Repression of Fyn-related kinase in breast cancer cells is associated with promoter site-specific CpG methylation
}

\author{
Edward T. Bagu ${ }^{1,2}$, Sayem Miah ${ }^{1,3}$, Chenlu Dai ${ }^{1}$, Travis Spriggs ${ }^{1}$, Yetunde \\ Ogunbolude $^{1}$, Erika Beaton ${ }^{1,2}$, Michelle Sanders ${ }^{1,2}$, Raghuveera K. Goel ${ }^{1}$, Keith \\ Bonham $^{1,2}$, Kiven E. Lukong ${ }^{1}$ \\ ${ }^{1}$ Department of Biochemistry, College of Medicine, University of Saskatchewan, Saskatoon, Saskatchewan, S7N 5E5, Canada \\ ${ }^{2}$ Cancer Research Unit, Health Research Division, Saskatchewan Cancer Agency, and Division of Oncology, College of \\ Medicine, University of Saskatchewan, Saskatoon, SK S7N 4H4, Canada \\ ${ }^{3}$ Current address: Stowers Institute for Medical Research, Kansas City, MO 64110, USA
}

Correspondence to: Kiven E. Lukong, email: kiven.lukong@usask.ca

Keywords: fyn-related kinase, $F R K, B R K$, breast cancer, triple negative breast cancer

Received: September 27, 2016

Accepted: December 15, 2016

Published: January 06, 2017

\section{ABSTRACT}

The triple-negative breast cancer subtype is highly aggressive and has no defined therapeutic target. Fyn-related kinase (FRK) is a non-receptor tyrosine kinase, reported to be downregulated in breast cancer and gliomas, where it is suggested to have tumor suppressor activity. We examined the expression profile of FRK in a panel of $\mathbf{4 0}$ breast cancer cells representing all the major subtypes, as well as in 4 non-malignant mammary epithelial cell lines. We found that FRK expression was significantly repressed in a proportion of basal B breast cancer cell lines. We then determined the mechanism of suppression of FRK in FRK-low or negative cell lines. In silico analyses of the FRK promoter region led to the identification of at least 17 CpG sites. Bisulphite sequencing of the promoter region revealed that two of these sites were consistently methylated in FRK-low/negative cell lines and especially in the basal B breast cancer subtype. We further show that treatment of these cells with histone deacetylase inhibitors, Entinostat and Mocetinostat' promoted re-expression of FRK mRNA and protein. Further, using luciferase reporter assays, we show that both GATA3-binding protein FOG1 and constitutively active STAT5A increased the activity of FRK promoter. Together, our results present the first evidence that sitespecific promoter methylation contributes to the repression of FRK more so in basal B breast cancers. Our study also highlights the potential clinical significance of targeting FRK using epigenetic drugs specifically in basal B breast cancers which are usually triple negative and very aggressive.

\section{INTRODUCTION}

Breast cancer is the most common form of cancer affecting women worldwide, with 1.7 million new cases diagnosed each year [1]. Gene expression profiling has enabled the classification of breast cancer into four subtypes: human epithelial growth factor receptor 2-positive, luminal A and B, and basal or the triplenegative breast cancer [2]. Basal breast cancers cell lines have been subdivided into A and B sub-categories $[3,4]$. Basal A cell lines are associated with the up-regulation of several genes in the E-twenty six transformation-specific pathway (ETS) and mutations of the tumor suppressor genes BRCA1 and 2; while, basal B cell lines are claudin-low and display mesenchymal and stem cell-like characteristics [3, 4].

Fyn-Related Kinase (FRK) is a non-receptor tyrosine kinase coded by FRK located on chromosome 6q21-23, a region that displays loss of heterozygosity $(\mathrm{LOH})$ in nearly $30 \%$ of breast cancers $[5,6]$. FRK belongs to the breast tumor kinase (BRK) family kinases (BFKs) that includes BRK and SRMS [7, 8]. BFKs share a conserved intron-exon architecture distinct from that of their closest relatives, the Src family kinases (SFKs) [7, 9]. Like SFKs, FRK is functionally composed of 3 domains, Src homology 3 (SH3), SH2 and a kinase domain. FRK possesses an auto-regulatory tyrosine residue (Y387) within the activation loop of the kinase domain and a 
putative C-terminal regulatory tyrosine (Y497) that is conserved in SFKs $[10,11]$.

There is evidence that FRK functions as a tumor suppressor [7, 12]. Knocking down FRK in the immortalized non-tumorigenic mammary epithelial cell line, MCF10A, induced transformation [13, 14]; while, exogenous expression of FRK in breast and brain cancer cells inhibited cell proliferation, migration and invasiveness $[13,15,16]$. FRK regulates cell growth by interacting with and/or phosphorylating specific cellular proteins $[12,14,15,17]$. FRK was shown to interact with retinoblastoma protein (pRB), a tumor repressor gene, via the $\mathrm{A} / \mathrm{B}$ pocket, inhibiting the proliferation of breast cancer cells [18]. Over-expression of FRK in glioblastoma cells downregulated phosphorylated $\mathrm{pRB}$, leading to growth arrest in the G1-phase [19]. FRK was later shown to inhibit cell proliferation, invasion and colony formation in breast cancer cells devoid of pRB by the phosphorylation and stabilization of tumor suppressor PTEN [13]. Interestingly, the depletion of Frk expression in mice had no effect on tumor formation [6]. There are suggestions that FRK may be oncogenic in some cancers [12].

Previous analyses of FRK in breast cancer cells/ tissues reported differential expression patterns $[9,20]$. FRK was reported to be repressed in a panel of 21 invasive breast carcinoma tissues and in $20 \%$ of invasive ductal carcinoma tissues [21, 22]. Pajeret al. reported that provirus-induced insertional mutations in the frk promoter increased frk expression in chicken lung sarcomas [23].

At present, the mechanisms regulating the expression of FRK in breast cancer are unknown. Epigenetic alterations in tumor suppressor genes have been identified in breast and other forms of cancer [24, 25]. Aberrant promoter hypermethylation is a frequent event in the silencing of several tumor suppressor genes including BRCA1 and spleen tyrosine kinase in various cancers [26-30]. In this study, we investigated the expression of FRK and its promoter methylation status in breast cancer cell lines. We found that the FRK promoter is methylated at specific $\mathrm{CpG}$ sites in FRK-low/negative breast cancer cell lines and demonstrated that histone deacetylase inhibitors reactivated the expression of FRK in these cells.

\section{RESULTS}

\section{FRK levels are repressed in a subset of human breast cancer cells}

Previous work produced conflicting data regarding the expression of FRK in human breast cancers and cell lines [9, 31-33]. To clarify this, we examined the expression of FRK in 44 cell lines. In Figure 1A to 1C, we present results for 20 cell lines with the highest and lowest
FRK expression. Most of the low FRK expressing breast cell lines were the basal B cell lines (MDA-MB-231; HBL100; BT549; Hs578T; HCC1395), some luminal (MDA-kb2, HCC1419) and basal A (DU4475) cells had low levels (Figure 1A to 1C). Based on the densitometry analysis of immunoblots of 37 cell lines (Supplementary Figure 1A), mean FRK levels were lower in the basal $\mathrm{B}$ as compared to either luminal or basal A cell lines $(P<0.05$; Figure 1D). FRK transcript levels were correlated with protein levels $(n=37, \mathrm{R}=0.63 ; P<0.05)$. Loss of FRK expression is more prevalent in the basal $\mathrm{B}$ breast cancers than other subtypes. Taken together, our data indicate that FRK is differentially expressed in breast cancer and the loss of FRK expression is more prevalent in the basal B breast cancers than other subtypes.

\section{The expression of $F R K$ in breast cancer cells correlates with site-specific promoter methylation}

FRK is a candidate tumor suppressor [15, 17, 34]. Aberrant methylation of $\mathrm{CpG}$ sites in the promoter region of tumor repressor genes is frequently observed in most cancers [35-37]. We therefore hypothesized that DNA methylation decreased the expression of $F R K$ in a subset of breast cancer cells. We analyzed the DNA sequence of the $F R K$ promoter $(+447 /-1357)$ using bisulphite primers that span regions, $+464 /-502$ and $-541 /-1112$ relative to the transcriptional start site (TSS/+1; Figure 2A). The $F R K$ promoter is devoid of a classic $\mathrm{CpG}$ island; however, there are $17 \mathrm{CpGs}$, from position +391 to $-959 \mathrm{bp}$, which we numbered accordingly (Figure 2B). In Figure 2B, we show 19 of the 34 breast cancer cell lines with the highest $(n=8)$ and lowest $(n=9)$ FRK expression levels. MCF10A and MCF12 are non-transformed mammary epithelial cell lines and both displayed varied methylation status. The FRK promoter region, +391 to -350 , was extensively methylated in cells that expressed low as compared to high FRK levels, with exception of the luminal breast cancer cell lines, HCC1419 and ZR-75-1 (Figure 2B). In the latter two cell lines the reverse methylation patterns were seen (Figure 2B). Two CpGs, 11 and 12 at sites -258 and -350 respectively, of $F R K$ promoter were consistently methylated in cells expressing low as compared to high FRK levels (Figure 2B). In the 36 cell lines analyzed, the incidence of methylation at CpGs, 11 and 12, sites -258 and -350 respectively was $27.8 \%$. Interestingly, $\mathrm{CpG} 11$ at site -258 from the TSS/ +1 was hemi-methylated in $16.7 \%$ of the cell analyzed. CpGs in the distal promoter region (-675/-959) were methylated in all the breast cancer cells except the basal B, immortalized non-transformed cell lines MCF12 (Figure 2B). Overall, our data indicate that CpGs 11 and 12, at sites -258 and -350 are crucial for the expression of $F R K$, and suggest the FRK promoter methylation is site-specific. 


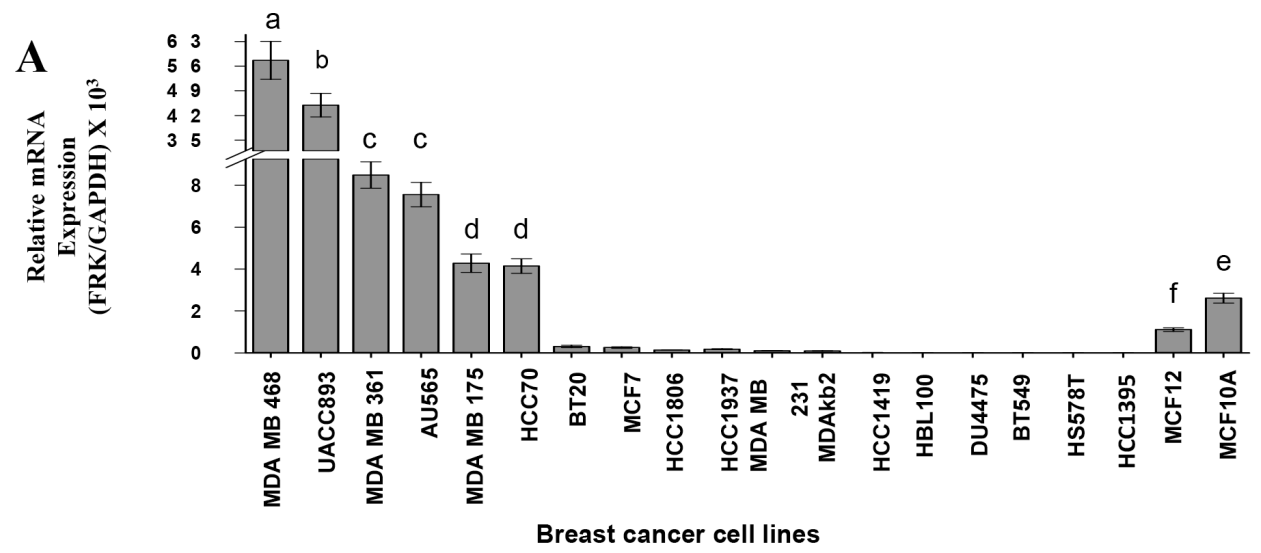

B
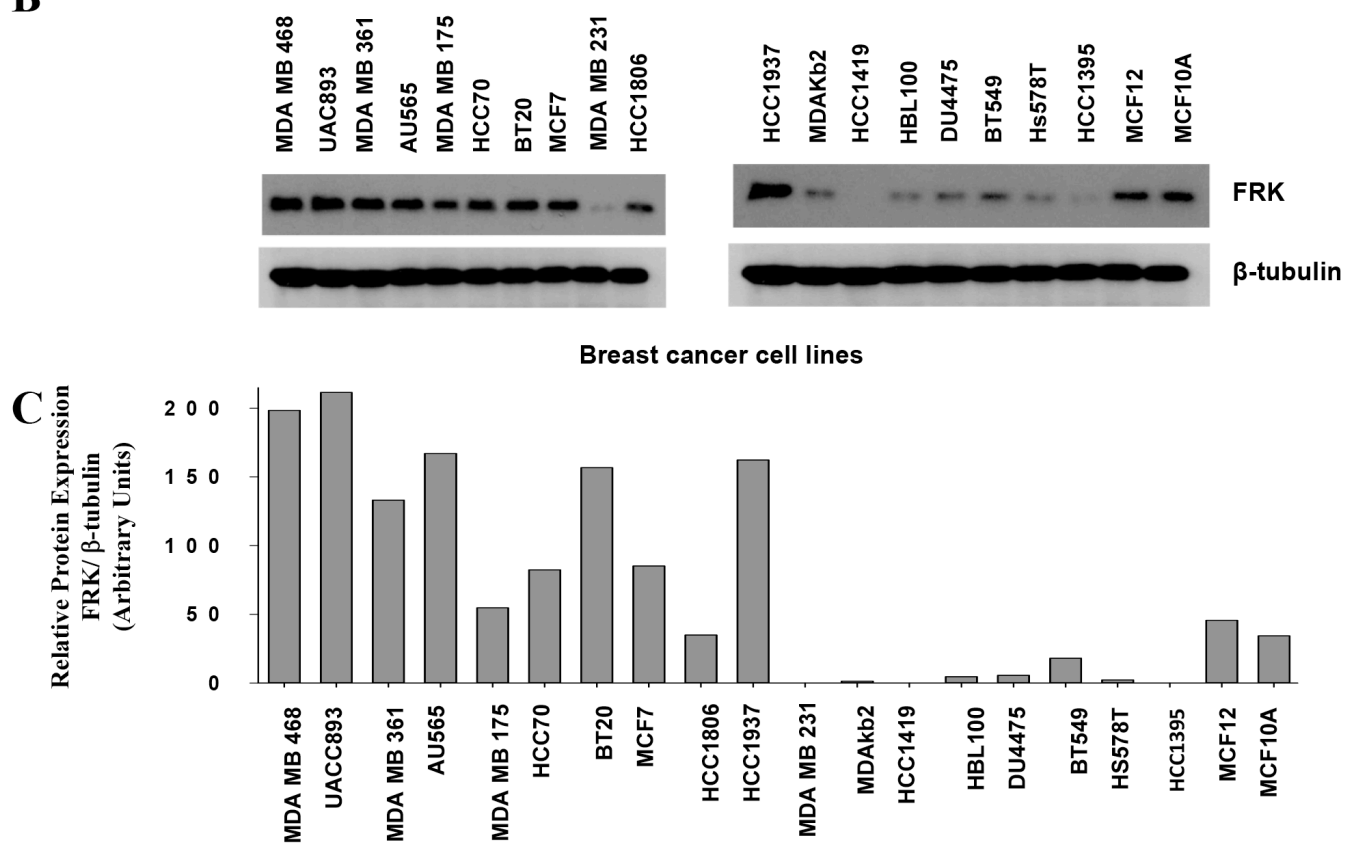

D

Breast cancer cell lines

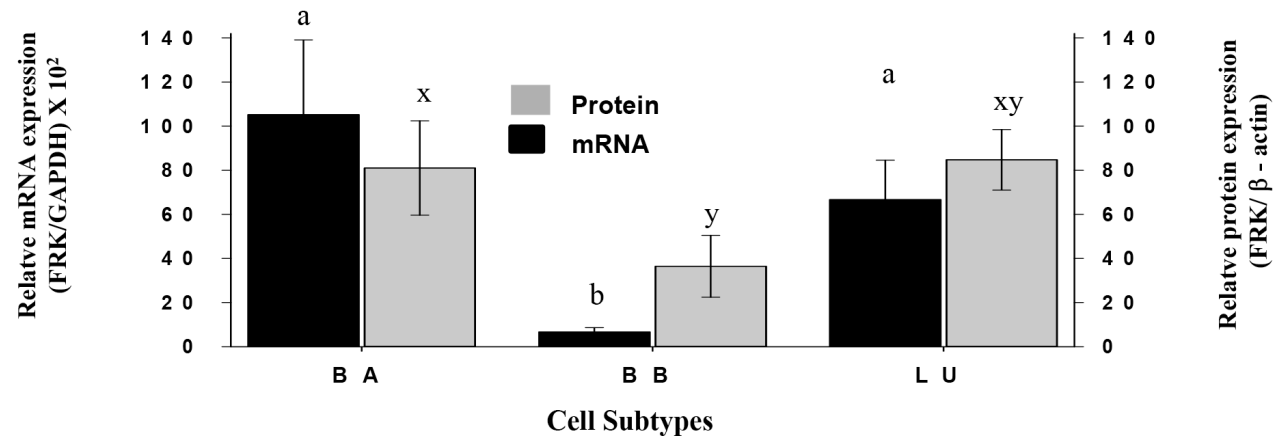

Figure 1: FRK levels are repressed in a subset of human breast cancer cells. (A) $F R K$ transcript levels relative to that of $G A P D H$ in each breast cancer cell line was assessed by qRT-PCR and then normalized to that of the HCC1395 breast cancer cells to determine the relative FRK transcript abundance. (B) FRK protein levels in each cell was analyzed from the cell lysates by immunoblotting using an FRK antibody (Santa Cruz), $\beta$-tubulin, a house keeping gene was used as a loading control. (C) Mean protein expression levels from (B) were quantified by densitometry and presented as the relative FRK/ $\beta$-tubulin expression using arbitrary units. (D) The mean relative expression of FRK (mRNA and protein) and $\beta$-actin levels in 37 breast cancer cell lines that were classified in the three cohorts Luminal (LU), Basal A (BA) and Basal B (BB) breast cancer cells. The mean relative protein expression levels were quantified by densitometry analysis of immunoblots in the Supplementary Figure 1A. The FRK expression was determined relative to $\beta$-ACTIN, a house keeping gene. Data is presented as Mean $\pm \mathrm{SEM}$, different superscripts a-z are used to indicate significant differences across means $(\mathrm{a}-\mathrm{Z}=P \leq 0.05)$. 


\section{Decitabine induces the expression of $F R K$ in breast cancer cells}

Decitabine (DAC) was shown to re-activate the expression of silenced genes in tumour cells by passive inhibition of DNA methyltransferase (DNMT) 1 $[35,37,38]$. We therefore examined if DAC would reactivate the expression of $F R K$ in 4 breast cancer cell lines (BT549, HCC1395, Hs578T and MDA-kb2) with extensive $F R K$ promoter methylation and low FRK expression. In all cases $F R K$ expression was increased following treatment with DAC $(P<0.05$; Figure $3 \mathrm{~A})$. FRK protein levels were also elevated in $\mathrm{HCC} 1395$, Hs578T and MDA-kb2 cells (Figure 3B and 3C). Our

A

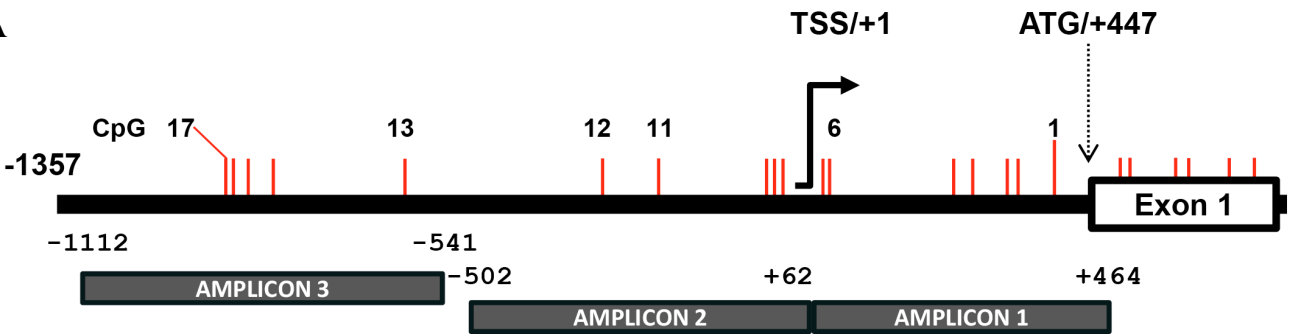

B

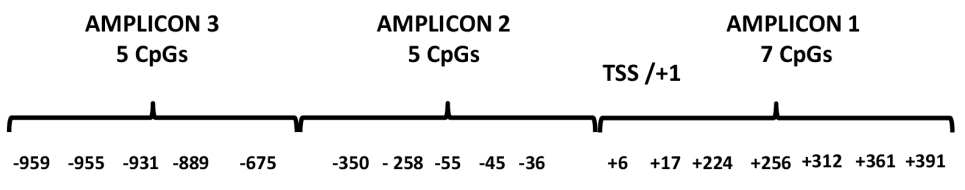

Subtypes Cell lines

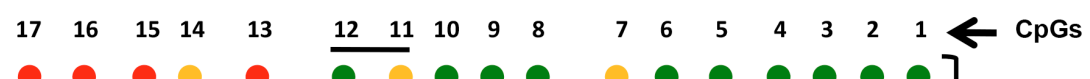

BA MDA-MB-468

LU UACC893

LU ZR-75-1

BA $\mathrm{HCC} 1954$

LU MDA-MB-361

LU AU565

LU MDAMB175

BA $\mathrm{HCC} 70$

BB MCF 12*

BB MCF10A*

$\circ \bigcirc 00$

○ 000

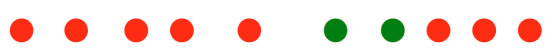

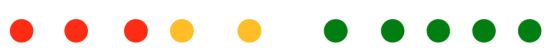

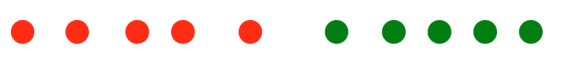

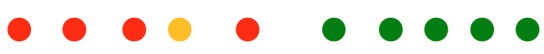

000

- 100

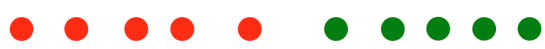

000

0000

0000007

000000

FRK
Levels

BB MDA MB 436

O 0

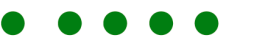

000000

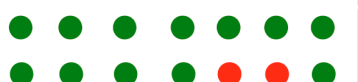

- HIGH

BB MDA-MB-231

LU MDA-kb2

LU HCC1419
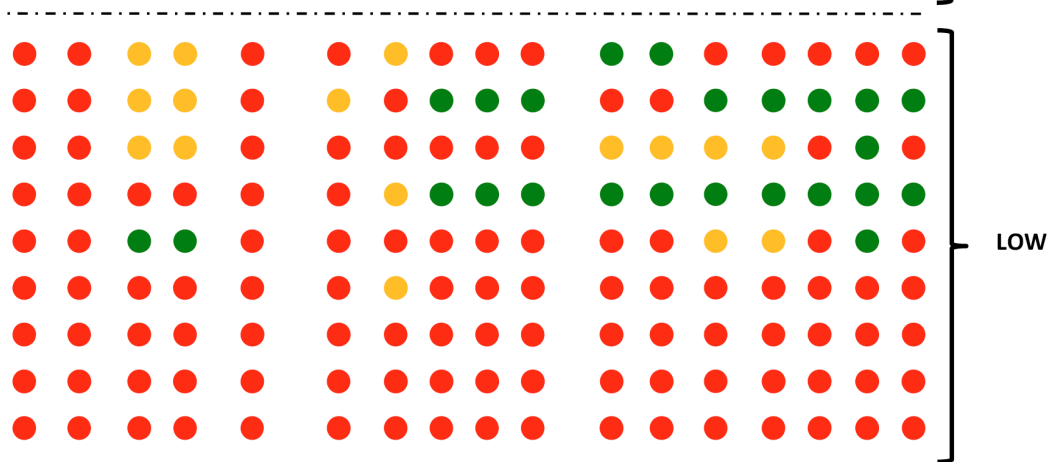

Figure 2: The expression of $F R K$ in breast cancer cells correlates with site-specific promoter methylation. (A) A schematic representation of the FRK promoter region, showing $\mathrm{CpG}$ sites as vertical red lines. Methylation specific primers were designed spanning the 2 regions, $+464 /-502$ and $-541 /-1112$ of the $5^{\prime}$ un-translated region (UTR) and the non-coding region up-stream up stream of exon 1 (ATG/+447), using a bioinformatics tool 65. (B) The methylation status of $17 \mathrm{CpG}$ sites, numbered 1 to 17 , from +391 to -959 bp of the transcriptional start site (TSS /+1) was determined. Genomic DNA was extracted from breast cancer cell lines or cell lines derive from normal epithelium (MCF10A and MCF12) with either low or high FRK mRNA expression and treated with sodium bisulfite, the DNA sequence of each amplicon was then determined to evaluate the methylation status of each of the $17 \mathrm{CpGs}$ in the FRK promoter region numbered from +391 to -959 of the TSS/ +1 . Red, green and orange circles represented the methylated, non-methylated and differentially methylated CpG sites (hemi-methylated), respectively. Asterisks (*) refers to the cell lines MCF10A and MCF12 that are derived from normal human breast epithelium. 

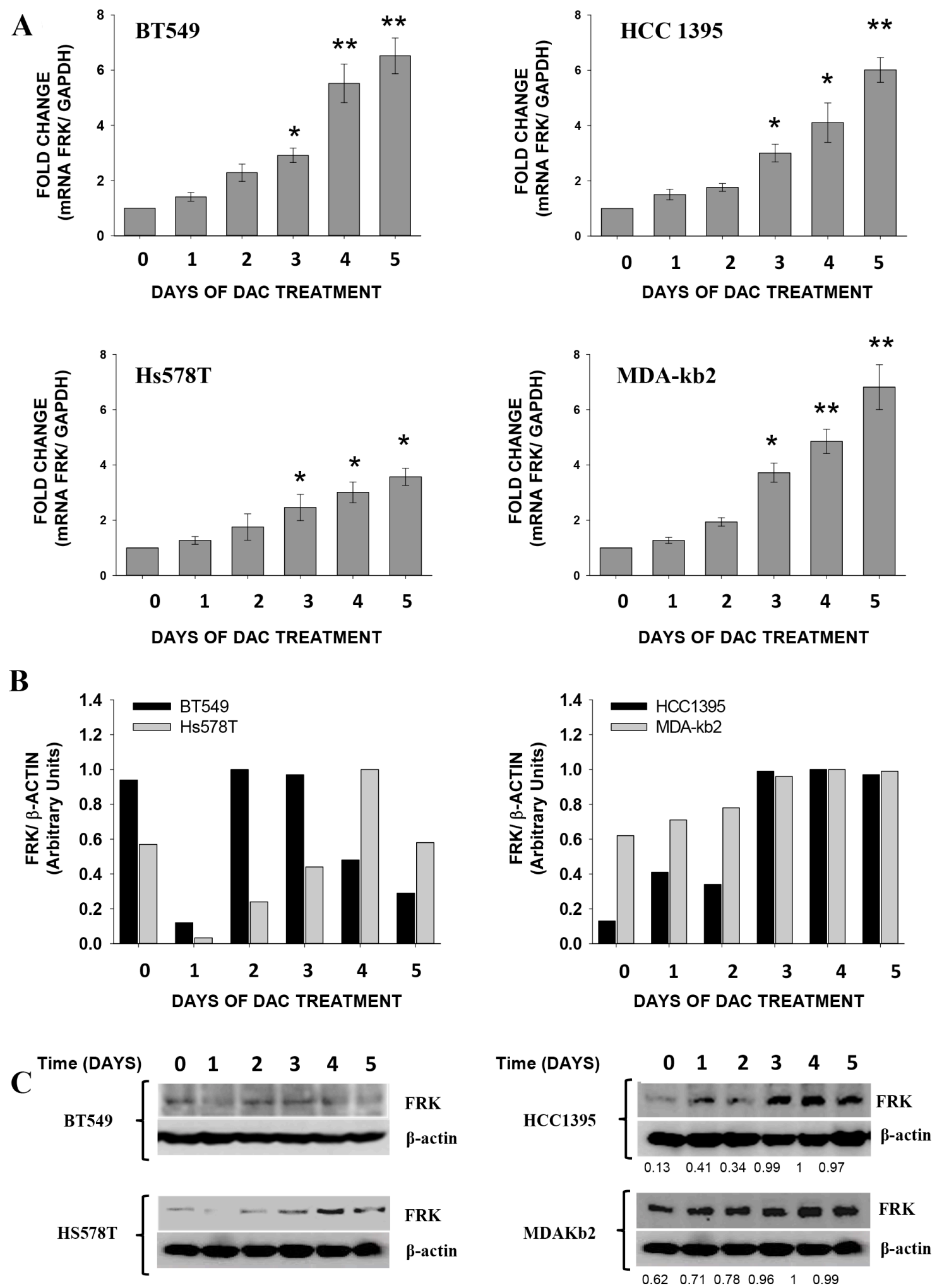

Figure 3: Decitabine (DAC) induces the expression of $\boldsymbol{F R K}$ in breast cancer cells. Breast cancer cells were treated with either $5 \mu \mathrm{M}$ (Hs578T cells) or $10 \mu \mathrm{M}$ (HCC1395 and MDA-Kb2 cells) of DAC every day for different durations indicated on the $\mathrm{x}$-axis. (A) FRK mRNA was extracted and quantified by qRT-PCR, FRK expression was determined relative to the GAPDH, then the fold change calculated relative to the controls. Data is presented as Mean \pm SEM, asterisks represent mean values greater than controls $\left(* P \leq 0.05\right.$ and $\left.{ }^{*} P \leq 0.01\right)$. (B) Densitometry analysis of the immunoblots of the FRK protein levels. (C) The FRK protein levels in each cell lysate was analyzed by immunoblotting using an FRK antibody. The mean relative protein expression levels were quantified by densitometry analysis of immunoblots. The FRK expression was determined relative to $\beta$-ACTIN, a house keeping gene and in each cell line normalized with the highest density ratio in each blot (1). 
data therefore demonstrates that DAC induces the expression FRK in cells with low FRK expression levels and extensive promoter CpG-methylation and our findings are consistent with the notion that the methylation status of the FRK promoter is essential for gene expression.

\section{HDAC inhibitors increase the expression of FRK in breast cancer cells}

Histone Deacetylase Inhibitors (HDIs) have been shown to activate silenced genes including $C D K N 1 A$, CDKN2A,SALL3, RARb2, TERT and GATA4, in the human cancer cells by active DNA demethylation of their respective promoters [39-41]. To determine whether the methylation status of FRK can be reversed by exposure to HDIs, we examined the effect of HDIs, Mocetinostat and Entinostat, on BT549, HCC1395, Hs578T and MDA-kb2 cell lines with extensive promoter methylation and low FRK expression levels. In all cases, the HDIs increased FRK levels 12 to 24 hours post-treatment $(P<0.05$; Figure 4). Although an increase in FRK protein was only seen in the BT549 cells, at 12 and 24 hours post-treatment $(P \leq 0.05$; Figure 4$)$, our data as a whole demonstrates that both Mocetinostat and Entinostat effectively relieved the epigenetic silencing of FRK in cells with extensive promoter CpG-methylation and low FRK expression levels.

\section{Epigenetic drug alters the $\mathrm{CpG}$ methylation status of the FRK promoter}

In order to evaluate whether the reactivation of FRK expression in breast cancer cells by epigenetic drugs was associated with promoter $\mathrm{CpG}$ demethylation, BT549 and Hs578T were evaluated after 5 days of 24 hourly treatments with DAC, and in the BT549, 24 hours post-treatment with Entinostat (Figure 5A). Treatment with DAC partially demethylated $\mathrm{CpG} 7$, at position +6 in Hs578T cells but had no effect in the BT459 cells (Figure 5B). Treatment of BT549 cells with Entinostat demethylated CpGs 11 and 12, at positions -258 and -350 , respectively (Figure 5C). Based on our observation therefore promoter site-specific de-methylation of CpGs 11 and 12 is important for the up-regulation of $F R K$ in breast cancer.

\section{The promoter regions proximal to CpGs 11 and 12 are crucial for the transcription of $F R K$}

Prior to this study, little was known regarding the transcriptional regulation of human FRK. Using the USCS database (http://genome.ucsc.edu/), we determined the FRK promoter region and TSS/+1. In order to know if the CpGs sites implicated above play a role in $F R K$ transcription we cloned the $F R K$ promoter fragment $(-2832 /+194 b p)$ along with deletion constructs into a pGL3-basic vector (Promega Corporation; Figure 6).
The reporter constructs were transiently transfected into AU565 and HCC70 cell lines, with high endogenous FRK levels. In both cells, promoter activity decreased following internal deletions of the $F R K$ promoter $(P<0.05$; Figure $6 \mathrm{~B})$. The decrease in activity indicated the presence of regulatory sites within the deleted regions, $-380 / 306$ and $-299 /-117 \mathrm{bp}$, that are crucial for the transcription of $F R K$.

The promoter regions $-374 /-317$ and $-299 /+89 \mathrm{bp}$, defined as site I and II, respectively, were then interrogated for regulatory elements using the program Multi-genome Analysis of Positions and Patterns of Elements of Regulation (http://ecrbrowser.dcode.org; Figure 6C). The putative DNA binding sites for transcription factors GFI1, STAT5A, TST1 and PAX overlapped CpG 12 (Table 1). Site-mutations M5, M7 and M8 within region -374/-317 of the full-length FRK promoter decreased its activity in the AU565 and HCC70 cells $(P<0.05$; Figure 6D). Mutations M5, M7 and M8 altered the canonical STAT binding sequence TTC-[N] $]_{3-6}$-GAA $[42,43]$.

Analysis of site II revealed potential binding sites for E2F1, HNF6, and GATA3 proximal to CpG 11 (Table 1). Tri-nucleotide mutations M9 and M10, within the region $-283 /-134$ of the full length FRK promoter decreased its activity in theAU565 and HCC70 cells $(P<0.05$; Figure 6C and 6D). Mutation M9 altered the canonical GATA3 binding sequences WGATAR, where $\mathrm{W}=\mathrm{A}$ or $\mathrm{T}$ and $\mathrm{R}=\mathrm{A}$ or G [44]; while, mutation M10 altered the canonical E2F1 binding sequences 5'-TTTSSCGS-3', where $S=C / G$ [45]. Our data indicate that the DNA binding sites of STAT5A, E2F1, and GATA3 are crucial for FRK transcription.

\section{Constitutively active STAT5A up-regulates the FRK promoter activity}

To determine if the STAT5A-DNA binding site was biologically relevant, we examined the effects of STAT5A on FRK promoter activity by co-transfections in AU565 cells (Figure 7A). The activity of the full length FRK promoter construct increased by 3-4-fold in the presence of constitutively active STAT5A (CA-STAT5A, $P<0.05$; Figure 7B). Co-transfection of the FRK promoter with either wild type (wt) STAT5A, Wt-STAT5B or CA-STAT5B had no effect on promoter activity (Supplementary Figure 6A). The FRK reporter constructs in which the STAT5A response element was either deleted $(-308,-81,+89$ and Mt-74) or mutated (STAT5A-Mt), were non-responsive to the CA-STAT5A $(P>0.05$; Figure 7B). The transactivation potential of STAT5A was boosted by internal deletions in constructs Mt-182 and Mt-235 (Figure 7B). This increased response to CA-STAT5A indicates this region may contain negative regulatory elements of STAT5A trans-activation. STAT5A transactivates the $F R K$ promoter through its putative DNA binding motif, $-355 /-331$. We concluded that in breast cancer cells STAT5A up-regulates the transcriptional expression of FRK. 
A

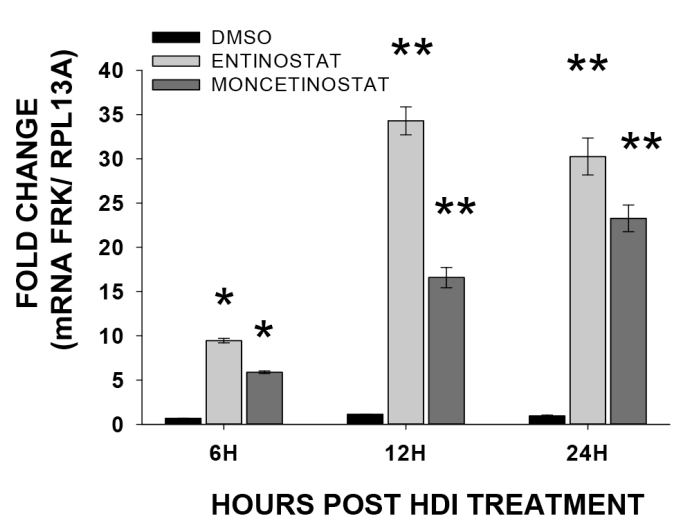

B

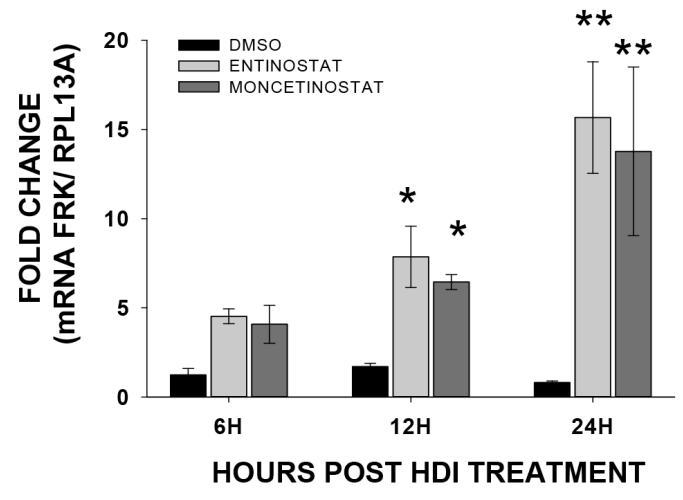

HCC1395
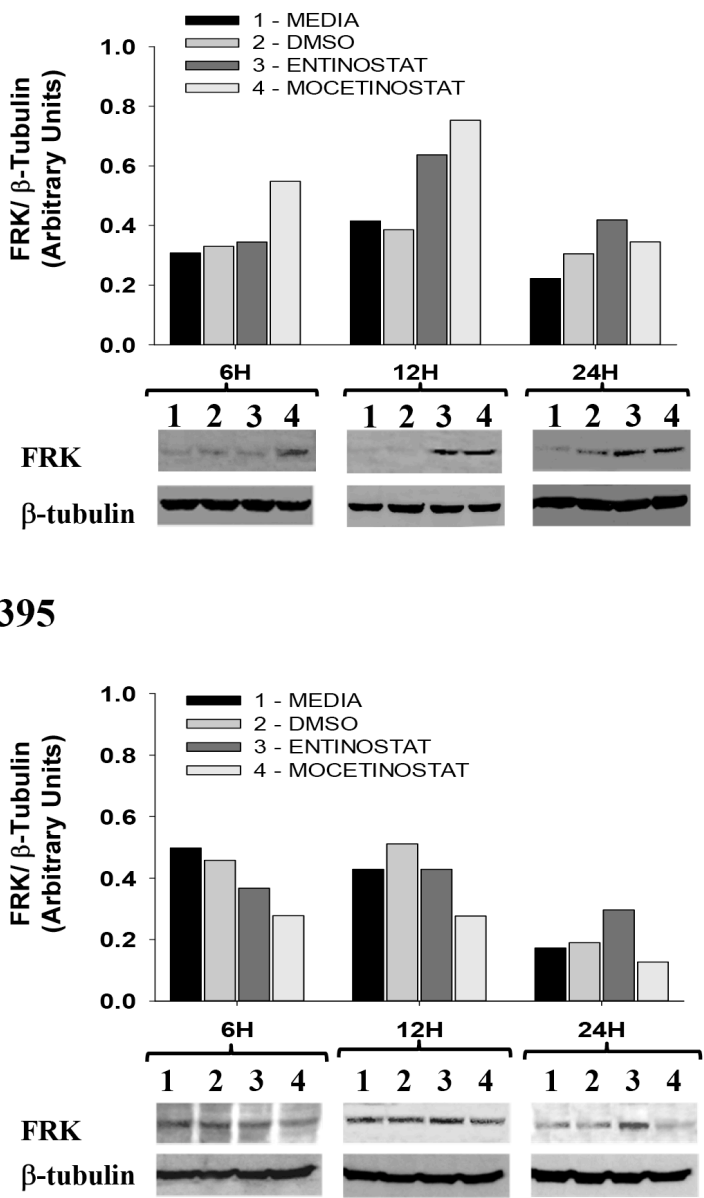

C

Hs578T
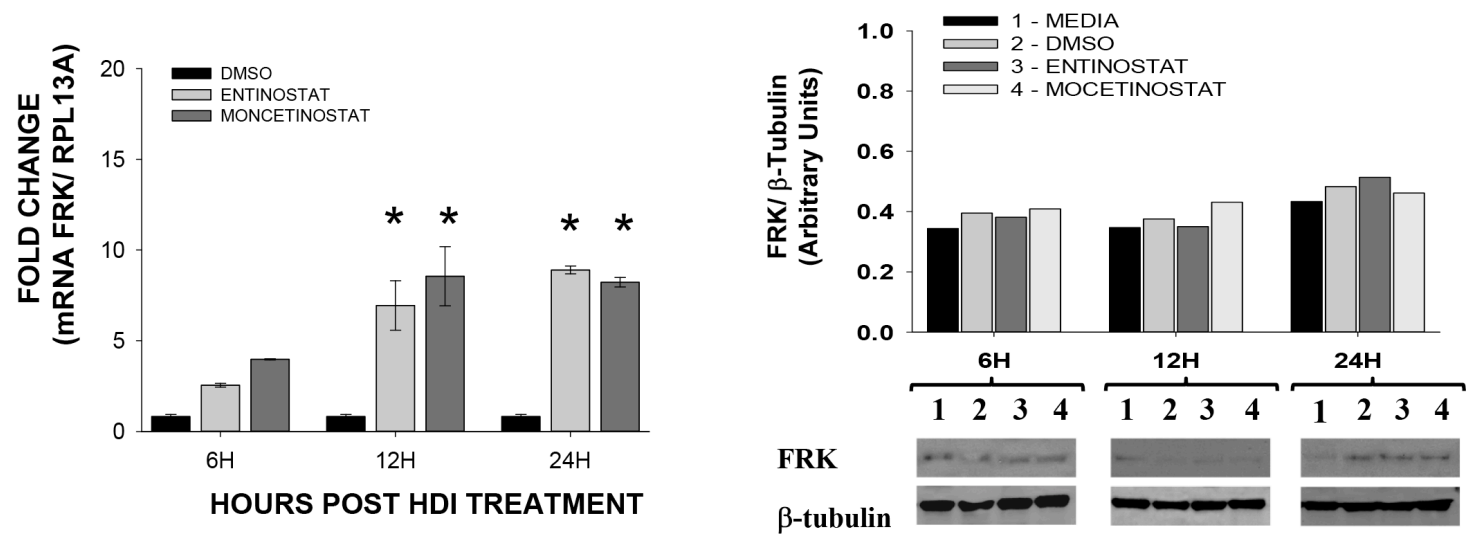

Figure 4: Histone deacetylase Inhibitors induces the expression of $\boldsymbol{F R K}$ in breast cancer cells. Breast cancer cellsBT549 (A), HCC1395 (B) and Hs578T (C) were treated with either Entinostat (MS275; $2 \mu \mathrm{M}$ ) or Mocetinostat (MGCD0103; $1 \mu \mathrm{M}$ ) dissolved in DMSO, for the time periods of 6,12 and 24 , hours, indicated on $\mathrm{x}$-axis as $6 \mathrm{H}, 12 \mathrm{H}$, and $24 \mathrm{H}$ respectively; while, controls at all the given time points received the vehicle (DMSO; $0.2 \mu \mathrm{l} / \mathrm{ml}$ ). To evaluate the relative FRK transcript abundance post-treatment, the FRK transcript levels in cells were determined relative to that of the house keeping gene, (Ribosomal Protein L13a) RPL13A using qRT-PCR. The fold change was then calculated relative to the controls in each experiment. Data is presented as Mean $\pm \mathrm{SEM}$, asterisks represent mean values greater than controls $\left(* P \leq 0.05\right.$ and $\left.{ }^{*} P \leq 0.01\right)$. The FRK protein levels in each cell lysate was analyzed by immunoblotting using an FRK antibody, the mean relative protein expression levels were then quantified by densitometry analysis of immunoblots. The FRK expression was determined relative to $\beta$-TUBULIN, a house keeping gene and presented as arbitrary units. 


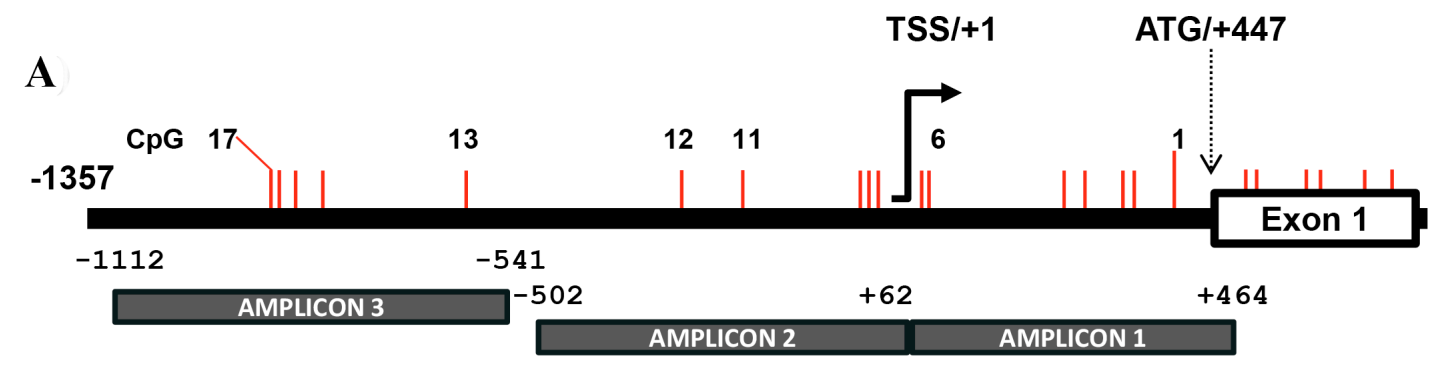

\section{B}
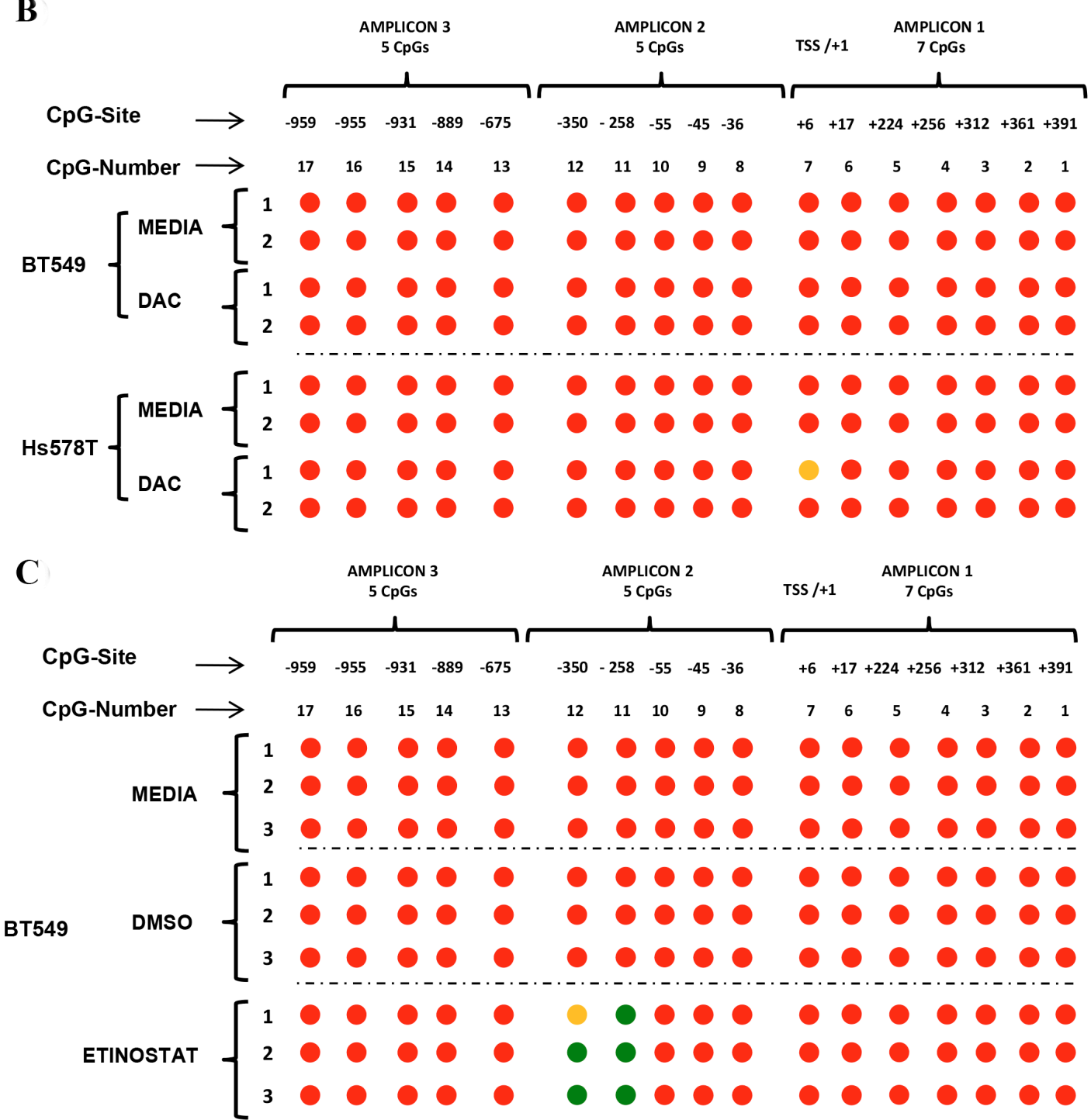

Figure 5: Epigenetic drugs alter the CpG methylation status of the FRK promoter. (A) A schematic representation of the FRK promoter region up-stream of exon 1, showing the $17 \mathrm{CpG}$ sites from the translation start site (ATG) at site +447 . Methylation specific primers were designed spanning the 2 regions, $+464 /-502$ and $-541 /-1112$ of the $5^{\prime}$ un-translated region (UTR) and the noncoding region up-stream up stream of exon 1 (ATG/+447), using a bioinformatics tool [65]. The $\mathrm{CpG}$ sites are represented as vertical red lines and numbered 1 to 17 , from +391 to -959 of the TSS/ +1 , respectively. (B) Breast cancer cells were treated with either 5 (Hs578T) or 10 (BT549) $\mu \mathrm{M}$ of DAC every 24 hours for 5 days; while, controls cells were cultured in their respective basal media. (C) BT549 breast cancer cells were treated with either Entinostat (MS275, $2 \mu \mathrm{M})$ or DMSO $(2 \mu \mathrm{l})$ for 24 hours; while, controls for each cell line were cultured in the respective basal media. Genomic DNA from Hs578T and BT549 cells was treated, with Sodium bisulfite, and used as a template for PCR. Amplicons generated were sequenced and the methylation status of the $17 \mathrm{CpG}$ sites in the FRK promoter determined. Circles filled with red represent methylated $\mathrm{CpG}$ sites, while green and orange circles represent non-methylated and differentially methylated $\mathrm{CpG}$ sites, respectively. Treatment of Hs578T cells with DAC partially demethylated CpG 7 at site +6 from the TSS; while, treatment of BT549 cells with Entinostat demethylated CpGs 11 and 12 at site $-258 /-350$ from the TSS. 

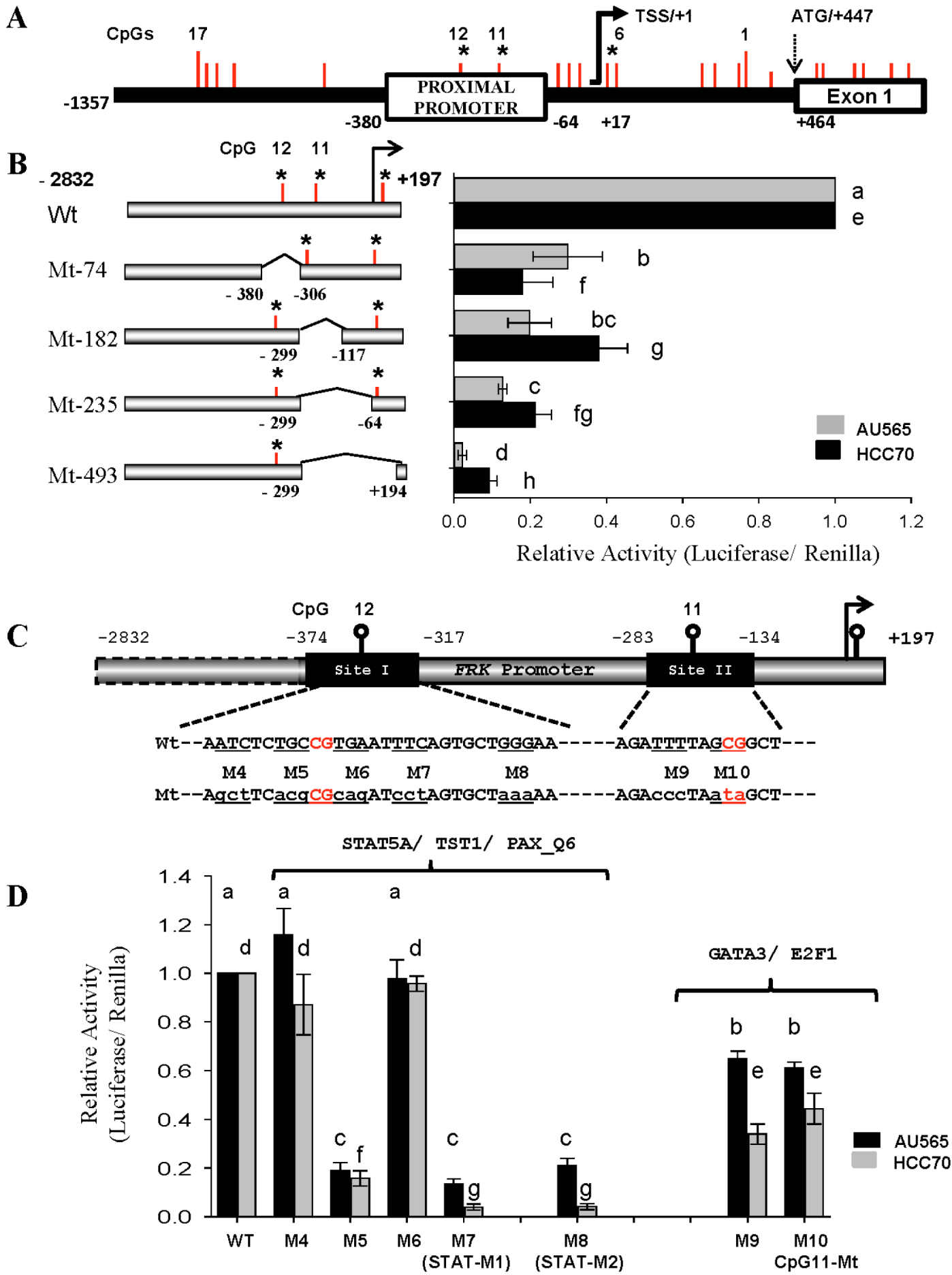

FRK PROMOTER CONSTRUCTS

Figure 6: The promoter regions proximal to CpGs 11 and 12 are crucial for the transcription of $F R K$. (A) A schematic representation of the $F R K$ promoter region from +447 to -1357 of the TSS/ +1 showing the $17 \mathrm{CpG}$ sites as vertical red lines along the promoter. (B) The CpG sites 11 and 12 are marked as vertical red lines within each of the constructs. The region deleted from each promoter construct is indicated along the breaks of each horizontal bar to the left of the y-axis for constructs mutant 74 (Mt-74), Mt-185, Mt 235 and Mt-493. (C) A schematic representation of the $F R K$ promoter regions flanking the CpG 12 and 11, sites I (-374/-317) and II (-283/ -134). The wild type (upper case) and the mutated nucleotides (lower case) are shown below each of the targeted sites. The human FRK promoter mutant constructs (Mt; M4 to M8 and M9 to M10 carried site-specific mutations as indicated in sequences below the site boxes (C). AU565 and HCC70 breast cancer cells were transfected with $495 \mathrm{ng}$ per well of various FRK promoter constructs of the human FRK promoter as indicated on the left of the $y$-axis (B) or below the $\mathrm{x}$-axis (D). Results are shown as relative activity of each construct with respect to the full length FRK promoter construct $-2832 /+197 b p$ (mean \pm S.E.M.). A different letter indicates a statistically significant difference. 
Table 1: Putative binding sites proximal to CpG sites 11 and 12 identified by using in silico analysis

\begin{tabular}{|c|c|c|c|}
\hline & Transcription factor & Putative sequence & Name of mutated sites \\
\hline \multirow{4}{*}{ SITE I } & GFI1 & gggAAAAAA_ATCTCTGCCGTGaat & M4, M5 and M6 \\
\hline & STAT5A & 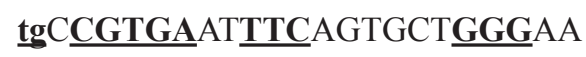 & M5, M6, M7 and M8 \\
\hline & TST1_01 & cgtgAATttcagtgc & M6 and M7 \\
\hline & PAX_Q6 & GTGAATTTCAG & M6 and M7 \\
\hline \multirow{3}{*}{ SITE II } & E2F_02 & TTTAGCGG & M10 \\
\hline & HNF6 Q6 & atATAGATTTta & M9 \\
\hline & GATA3 & ataGATTTTA & M9 \\
\hline
\end{tabular}

The underlined sites indicate the nucleotides that were mutated in constructs transiently transfected in the breast cancer cells.

\section{Friend of GATA 1 up-regulates the $F R K$ promoter activity}

Next, we investigated the biological relevance of the GATA-DNA binding site, also shown to be crucial for $F R K$ transcription (Figures 6 and 7A). To this end, we co-transfected various FRK promoter constructs and the GATA3 construct into AU565 cells (Figure 7A). We found that the FRK promoter activity of all constructs was repressed by GATA3 $(P<0.05$; Figure $8 \mathrm{~A})$, indicating the presence of other potential GATA response elements in the $F R K$ promoter. GATA proteins were shown to be modulated by FOG-1 and 2 [46, 47]. Co-transfection of the $F R K$ promoter with a vector coding the FOG-1 protein, resulted in the up-regulation all the FRK constructs except the empty pGL3-vector $(P<0.05$; Figure $8 \mathrm{~B})$. Interestingly, deletion of the STAT5A binding region that span the CpG 12 site (Mt-74) significantly decreased the transactivation of FRK by FOG1 as was observed when the GATA3 binding region that spun CpG 11 site (Mt-235) was deleted (Figure $8 \mathrm{~B}$ ). These findings indicate that the co-modulator of GATA3, FOG1, up-regulates FRK by overcoming the GATA3 driven repression of FRK.

\section{DISCUSSION}

The role of FRK in human cancer is unclear; however some reports have shown that its expression is lost in breast cancers and that its re-expression suppresses breast tumor growth [17]. To understand the expression pattern of FRK in breast cancer, we examined the levels of the transcript and protein in a panel of 40 human breast cancer cell lines and 4 non-malignant mammary epithelial cell lines. FRK levels were low or absent in about $20 \%$ of the cell lines, 6 of the 9 with low FRK levels belonged to the basal B category, 2 were classified as luminal and 1 basal A.

Epigenetic changes are one of the most important molecular aberrations in the pathogenesis of cancer $[24,48]$. Epigenetic repression is often associated with genes where the promoter has a high density of $\mathrm{CpG}$ sites (CpG-islands); however, the FRK promoter has a low $\mathrm{CpG}$ content with $27 \mathrm{CpG}$ sites spanning $3223 \mathrm{bp}$, from -2832 to
+391 . We determined the methylation status of the $17 \mathrm{CpG}$ dinucleotides in the FRK promoter (+391/-959 bp) for 19 cell lines. With the exception of the HCC1419 cell line, the $F R K$ promoter was highly methylated in breast cancer cell lines with low FRK expression. Methylation was largely absent in cell lines with high FRK, with exception of the breast cancer cell lines ZR-75-1 (Figure 2B) and CAMA-1 (Supplementary Figure 2). In breast cancer cells, ZR-75-1 and CAMA-1 the promoter region $(+391 /-959)$ was densely methylated even though the FRK (mRNA and protein) expression was high. However, the absence of methylation at CpGs 12 and 11 at sites -350 and -258 respectively was consistent in the two cell lines (ZR-75-1 and CAMA-1) with other high FRK expressing cell lines. We further performed in-silico analysis of breast cancer patient data from the Cancer Genome Atlas (TCGA) and established that the FRK proximal promoter region in tumors samples had a lower methylation density compared with the matched normal tissues (Supplementary Table 8 and Supplementary Figure 8A, 8B) [49]. Observations from both breast cancer cells and TCGA data led to the conclusion that the transcription repression of FRK was independent of the FRK promoter methylation density. Interestingly, two sites, CpG 11 and 12 at sites -258 and -350 from the TSS/+1, were methylated in the 9 of 36 cells with an incidence of $27.8 \%$. However, $\mathrm{CpG} 11$ site was more prone to hemi-methylation (16.7\%). All the 9 cell lines exhibited low FRK expression levels. It was apparent that methylation of sites 11 and 12 was associated with decreased FRK expression, suggestive of site-specific methylation. Site-specific methylation was previously cited as the mechanism behind hTERT and ANKRD11 repression in colorectal carcinoma and breast cancer, respectively [50].

Treatment of cancer cells with epigenetic drugs alters the chromatin landscape resulting in the differential expression of genes [51-54]. DAC, a demethylating agent, was reported to reactivate silenced genes by passively inhibiting the activity of DNMT [38]. The HDI, TSA acted in synergy with DAC in the induction of retinoic acid receptor $(R A R) \beta e t a$ and estrogen receptor-1 expression in MDA-MB-231 cells [55]. Inhibition of HDAC activity 


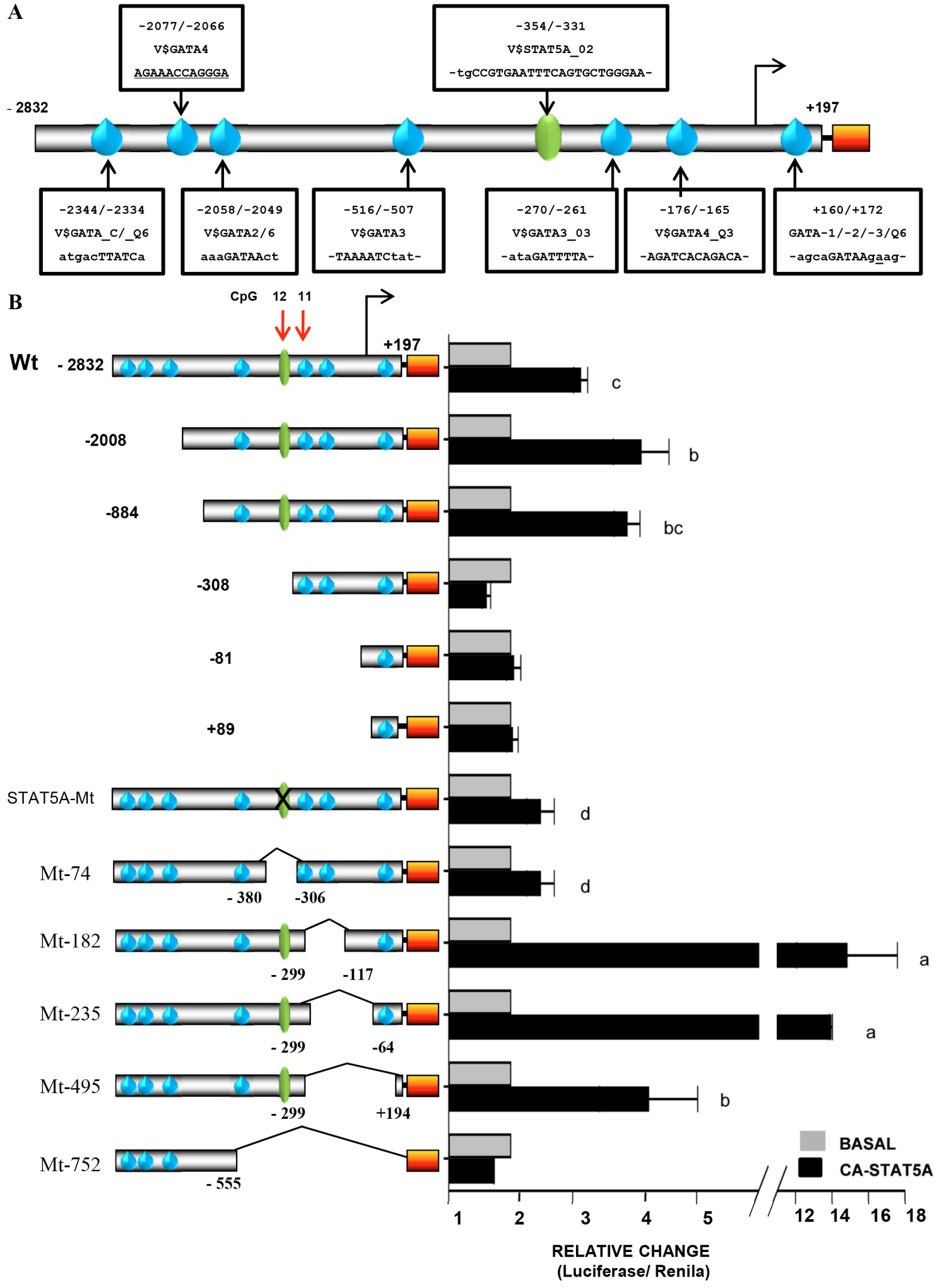

Figure 7: Constitutively active STAT5A up-regulates the FRK promoter activity. (A) A schematic representation of the FRK promoter region $-2832 /+197$, that was cloned up stream of the luciferase reporter gene (Orange box). The sequences of the putative binding sites of STAT5A and the GATA proteins (1, 2, 3, 4 and 6) are indicated along the promoter in boxes. (B) AU565 breast cancer cells were co-transfected with various $F R K$ promoter constructs (245 ng per well) as indicated on the left of the y-axis in the graph $8 \mathrm{~B}$ ) along with 250 ng per well of a construct that express the constitutively active STAT5A(CA-STAT5A). Total DNA per well was kept at $500 \mathrm{ng}$ per well. AU565 controls cells in each case were transfected with the empty pCDNA3 vector (Invitrogen). Results are shown as fold activation over control (mean $\pm \mathrm{SEM}$ ). The superscripts a-d indicates relative mean values that are significantly different $(P \leq 0.05)$. 
A

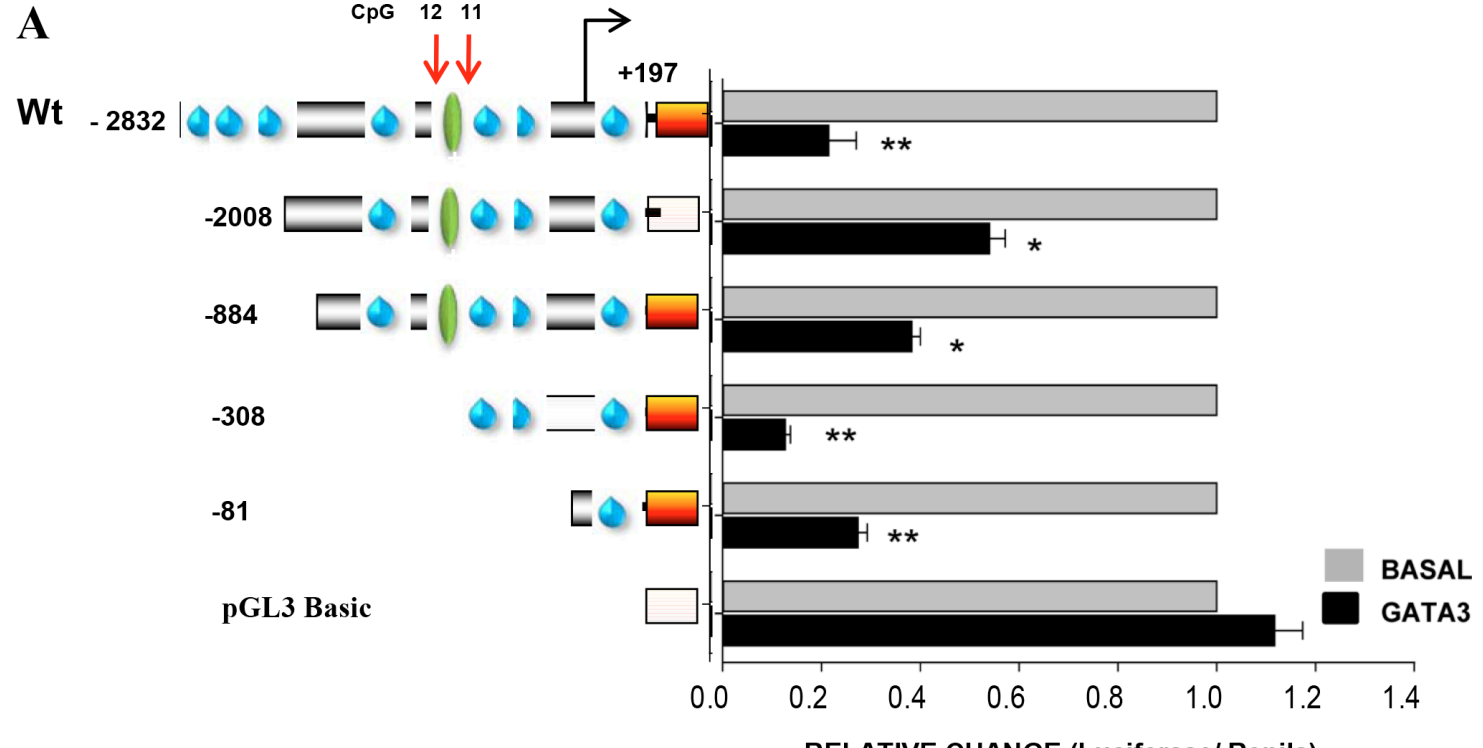

RELATIVE CHANGE (Luciferase/ Renila)

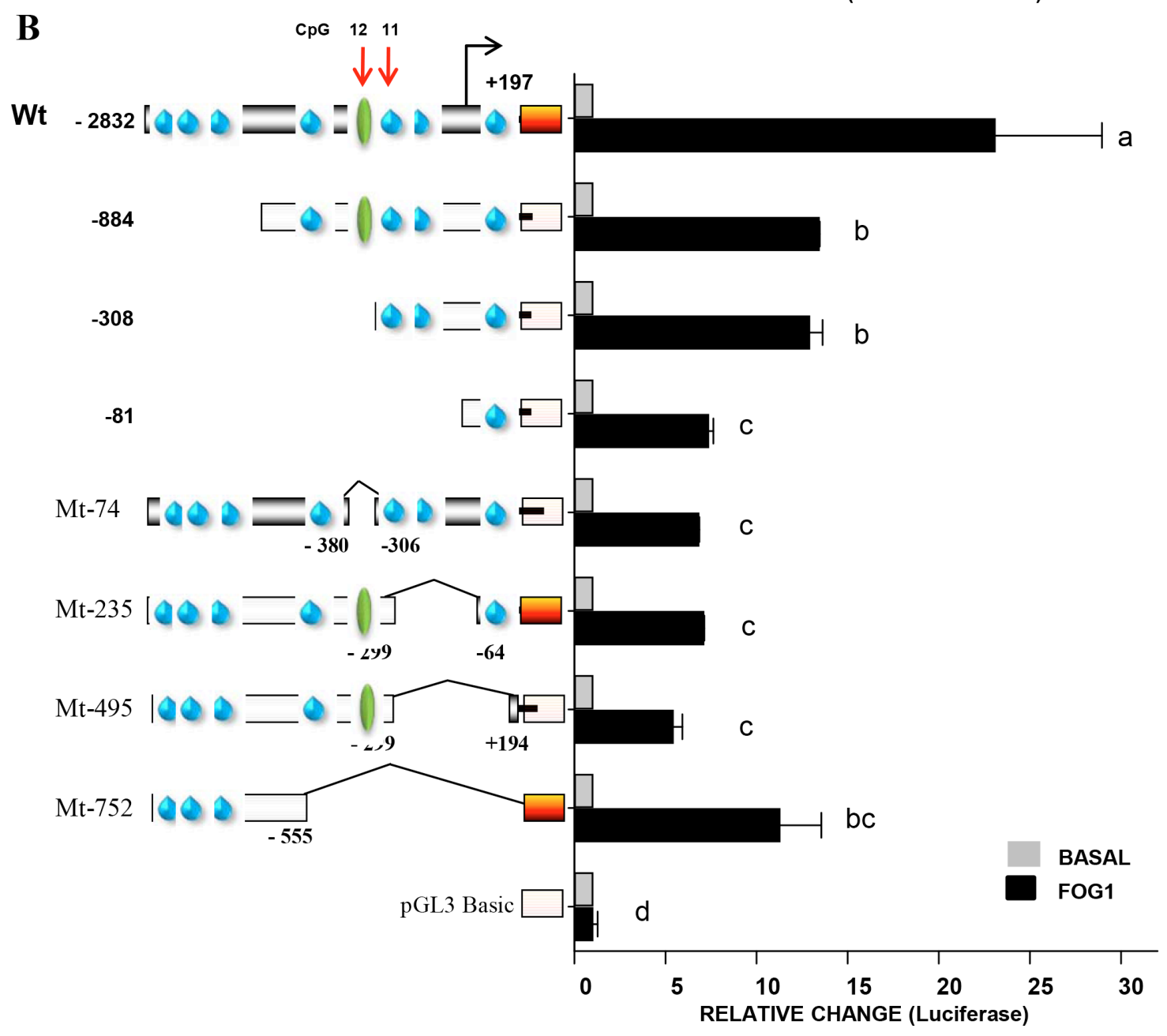

Figure 8: Friend of GATA 1 up-regulates the $\boldsymbol{F R K}$ promoter activity. AU565 breast cancer cells were co-transfected with $245 \mathrm{ng}$ per well of various $F R K$ promoter constructs as indicated on the left of the y-axis in the graphs along with $250 \mathrm{ng}$ per well of either the (A) GATA3 or (B) FOG1 expression vectors that code for one of the for the full length wild type proteins GATA3 and FOG1, respectively. AU565 controls cells in each case were transfected with the empty pCDNA3 vector (Invitrogen) and total DNA per well was kept at $500 \mathrm{ng}$. Results are shown as fold activation over control (mean $\pm \mathrm{SEM}$ ). The superscripts (a-d) indicate relative mean values that are significantly different $(P \leq 0.05)$. 
by HDIs such as TSA, Entinostat and Mocetinostat results in the re-expression of tumor suppressor genes [52-54]. In our preliminary studies, treatment of MDAMB-231 cells with DAC in combination with TSA, led to a lower induction of FRK as compared to DAC only (Supplementary Figure 4). DAC induced the expression of FRK in all the cell lines; however, in the BT549 cells unlike the other cell lines there was no increase in FRK protein levels. The decreased FRK protein levels in the BT549 cells could have been due to a drug induced translational defect. It was suggested that high concentrations of DAC were incorporated in both DNA and RNA leading to the formation of defective tRNAs and rRNAs thereby inhibiting protein synthesis [56].

Treatment with DAC resulted in a partial demethylation of $\mathrm{CpG} 7$ at position +6 in Hs578T cells but had no effect in BT549. It is therefore likely that DAC could have induced the expression of FRK without demethylating any of the $\mathrm{CpG}$ sites in the promoter region as was noted when the hypomethylated BT20 breast cancer cells were treated (Supplementary Figures 2 and 4). Decetabine was shown to up-regulate, $C D K N 1 A$ and $C D K N 2 D$ independent of promoter $\mathrm{CpG}$ demethylation $[57,58]$. The increased expression of $C D K N 1 A$ was linked to the demethylation of an upstream regulator P73, while activation of $C D K N 2 D$ was thought to be a consequence of global gene demethylation [57, 58]. Interestingly, treatment of the hypomethylated SKBR3 cells with DAC led to the down-regulation of FRK (Supplementary Figure 4). The response to DAC was cell specific.

Treatment of breast cancer cells with Entinostat and Mocetinostat resulted in 10 to 33-fold increase of FRK levels. The increase in FRK mRNA was translated into higher protein levels in BT549 cells. On evaluating the FRK promoter methylation status in the BT549 cells 24 hours post-treatment with Entinostat, CpGs 11 and 12 , at positions -258 and -350 , were demethylated. HDIs, TSA, depsipeptide and sodium butyrate, were shown to enhance the expression of genes such as CDKN2A, CDKN1A, SALL3, RARb2, TERT and GATA4 in human cancer cell lines by active DNA demethylation of their respective promoters [39-41]. In addition, depsipeptide decreased the binding of DNMT1 to the promoter, while sodium butyrate repressed MAP kinase I, down regulating the cellular levels of DNMT1 [39, 40]. Interestingly, treatment of the hypomethylated HCC 1419 cells with Entinostat and Mocetinostat also increased FRK expression (Supplementary Figure 4). It is likely Entinostat induced the expression of FRK via mechanisms other than promoter DNA demethylation. Treatment of BT549 with Entinostat displaced the chromatin repressive markers histone $\mathrm{H} 3 \mathrm{~K} 9 \mathrm{me} 3$ and $\mathrm{H} 3 \mathrm{~K} 27 \mathrm{me} 3$ from the FRK promoter (Supplementary Figure 5). Entinostat was shown to increase $\mathrm{H} 4$ acetylation [59]. Acetylation of histone H4 plays a primary role in the structural changes of the chromatin enhancing binding of transcription factors to their recognition sites within nucleosomes [60].
Prior to this study there was no report detailing the transcriptional regulation of $F R K$ in humans, therefore the significance of these methylated sites was unclear. Promoter regions that were crucial of the $F R K$ transcription activity were mapped using internal deletions, $-380 /-306$ and 299/-117 that contained the CpGs 12 and 11 , at site -350 and -258 , respectively. We determined that the DNA sequences proximal to $\mathrm{CpG} 12$ and 11 contained binding sites for specific transcription factors. Of great interest were sequences tgCCGTGAATTTCAGTGCTGGGAA and ataGATTTTA that span the promoter regions $-354 /-331$ and $-270 /-261$. These $F R K$ promoter sequences were consistent with the canonical binding sites for STAT5 (-354/-331) and GATA (-270/-261), TTC-[N] $]_{\mathrm{n}}$-GAA and WGATAR, respectively [42-44].

In this study, constitutively active (CA) STAT5A transactivated the $F R K$ promoter constructs with the putative STAT5A response element; however, STAT5B had no effect (Supplementary Figure 6A). It was suggested that a spacer (n) of greater than 4 nucleotides favored binding of STAT5A over STAT5B [42, 43]. The FRK sequence from -354 to -331 of the $\mathrm{TSS} /+1$ has a spacer of 7 nucleotides. Mutations (M7 and M8) and deletions of the sequence $-354 /-331$ ablated the transactivation of the promoter by CA-STAT5A in AU565 cells. Interestingly, Entinostat and Mocetinostat up-regulated the expression of $S T A T 5 A / B$ along with FRK levels (Supplementary Figure 5). It is likely that methylation $\mathrm{CpG} 12$ interferes with binding of STAT5A to its DNA sequence on the FRK promoter hence repressing $F R K$ expression in the breast cancer cells. Methylation of the STAT5A DNA-binding sequence in the $\alpha \mathrm{S} 1$-casein promoter was reported to repress the prolactin induced expression of the $\alpha \mathrm{S} 1$ casein during acute mastitis [61]. We noted that the transactivation potential of CA-STAT5A was boosted by deletions that span the CpG11 (constructs Mt-182 and Mt-235). It's therefore likely that the deleted sequence harbored a STAT5A repressor element. We established the region spanning the $\mathrm{CpG} 11$ at site -258 contained putative binding sequences for the GATA- and E2F- family of transcription factors, denoted as WGATAR, where $\mathrm{W}=\mathrm{A}$ or $\mathrm{T}$ and $\mathrm{R}=\mathrm{A}$ or $\mathrm{G}$ [44] and 5'-TTTSSCGS-3', where S $=\mathrm{C} / \mathrm{G}$, respectively [45]. Mutations $\mathrm{M} 9$ and M10 within the core sequence ATTTTAGCGG in the full-length promoter ablated the FRK promoter activity. The effectors coding for the full-length proteins GATA-3 and E2F-1 repressed the activity of the $F R K$ promoter (Figure 8A and Supplementary Figure 6B). This could explain why deletion of this region $-299 /-64$ led to the increased response of the FRK promoter to CA-STAT5A.

The activity of GATA proteins was previously shown to be modulated by FOG 1 and 2 [46, 47, 62]. Co-transfection of the FRK promoter with a vector encoding the full length FOG1 protein, up-regulated the FRK promoter activity of constructs with functional GATA sites. Interestingly, FOG-2 had no effect on the FRK promoter activity (data not shown). It is worth noting 
in-silico analysis of protein-protein interaction networks using STRING v9.1 (http://string-db.org/) shows a potential interaction of STAT5A with FOG1 but not FOG2 [63]. This could explain why deletion of the STAT5A binding region that spans $\mathrm{CpG} 12$ site (Mt-74) led to the decreased transactivation of FRK by FOG1 as was observed when the GATA3 binding region that span CpG 11 was deleted. We concluded that the repression of FRK in a subset of breast cancer cell lines was a consequence of methylation at specific $\mathrm{CpG}$ sites, -258 and -350. It is likely that methylation of $\mathrm{CpG} 11$ and 12 interfered with binding of STAT5A and GATA3 to their putative core sequences, with the repressive actions of the GATA3 reversed by FOG1. In this study, the basal expression of FRK across all the 40 cells was not correlated with the expression of either STAT5 (A/B) or GATA3/FOG1 (Supplementary Figure 7A-7D). It is worth noting that, with the exception of the Hs578T cells, all the low $F R K$ expressing cell lines had very low levels of $S T A T 5 A$, although this phenomenon was not exclusive to $F R K$-low cells. High FRK expressing cell lines like UACC893, ZR-75-1, MDA-MB-361, MDA-MB-175 and HCC1569 had low STAT5A levels. While GATA-3 expressions were also low in all the $F R K$-low breast cancer cells, with exception of MDA-kb2 and the HCC1419, likewise this was not limited to the $F R K$-low cells.

Our findings support the association of site-specific methylation of the FRK promoter with its reduced expression in breast cancer cells. The loss of expression was more prevalent in the basal breast cancer cell type. This suggests that loss of FRK expression may promote cancer growth or development in a particular cellular context. Our findings highlight the clinical relevance of epigenetic drugs in the re-activation of silenced tumor repressor genes in breast cancer.

\section{MATERIALS AND METHODS}

\section{Cell culture}

Breast cancer cell lines and non-tumorigenic cells derived from normal human breast epithelia were stratified into 3 different breast tumor phenotypes: Basal A (BA); Basal B (BB); and Luminal (LU) (Supplementary Table 1). All cells were cultured as recommended by American Type Culture Collection (ATCCA; Manassas, VA USA).

\section{Decitabine treatment}

BT549, HCC1395, Hs578T and MDA-kb2 cell lines were seeded in $10 \mathrm{~cm}$ plates were treated with either $5 \mu \mathrm{M}$ (BT549, Hs578T and MDA-MB-231) or $10 \mu \mathrm{M}$ (HCC1395 and MDA-kb2) of DAC (Sigma-Aldrich, Ontario Canada), every 24 hours, over a selected period $(1,2,3,4$, and 5 days). The culture media in all plates was replenished every 24 hours, prior to treatments with DAC. Concentrations of DAC used were determined using a dose response curve in which cells were treated with DAC every 24 hours for 3 days (Supplementary Figure 3). Treatment with DACwas initiated when cells attained a $70 \%$ confluence, cells were culturedfor 6 days and control cells were grown in their basic media.

\section{Entinostat and mocetinostat treatments}

Breast cancer cell lines BT549, HCC1395 and Hs578T were seeded in 21 different $10 \mathrm{~cm}$ plates as above. The cell lines were treated with either Entinostat ( $2 \mathrm{mM})$ or Mocetinostat $(1 \mu \mathrm{M})$ for 6,12 and 24 hours, while the control cells for each treatment time point received the vehicle DMSO $(0.2 \mathrm{~mL} / \mathrm{mL})$. Treatments were initiated when the cells attained $80 \%$ confluence.

\section{RNA isolation, reverse transcription, PCR and real time PCR}

Total RNA was isolated from cells using Trizol $^{(\mathrm{R})}$ as recommended by the manufacturer (Invitrogen Canada, Burlington, Ontario, Canada). cDNA was synthesized using the Thermo-scientific maxima first strand cDNA synthesis Kit (ThermoFisher Scientific, Lafayette, CO 80026, United States). The cDNA synthesized was used as a template in quantitative RT-PCR. The expression of FRKand housekeeping genes $G A P D H$ and $R P L 13 A$ was determined using TaqMan ${ }^{\mathrm{R}}$ probes Hs00176619_m1; Hs275991 and Hs04194366, respectively as recommended by manufacturer (Thermo Fisher Scientific). FRK expression was normalized to that of the house keeping gene detected within the same well by an Applied Biosystems ${ }^{\mathrm{TM}}$, Step One Plus qRT-PCR machine (Life Technologies, Burlington). The relative expression of $F R K$ to the house keeping gene (GAPDH or $R P L 13 A$ ) of each sample was then determined with respect to that of HCC1395.

\section{Immunoblotting}

Breast cancer cells were harvested and the FRK and $\beta$-actin protein expression in cell lysates detected as was previously published [64]. FRK was probed for using a mouse polyclonal antibody (Santa Cruz).

\section{Sodium bisulphate DNA modification and bisulphite sequencing}

Genomic DNA was isolated from cells using the DNeasy, Blood and Tissue Kit as recommended by the manufacturer (Qiagen, Hilden, Germany). The DNA was treated with Sodium bisulfite using the EpiTect ${ }^{\mathrm{R}}$ Bisulfite Kit according to the manufacturer's instructions (Qiagen, Hilden). The treated DNA (100 ng) was then used as a template in PCR reactions with bisulfite-PCR primers.

The FRK promoter region -1357 to +464 from the transcription site was analyzed using a bioinformatics 
tool [65]. Bisulfite-PCR primers were designed spanning the regions, $+464 /-502$ and $-541 /-1112$ of the FRK promoter TSS/+1 (Supplementary Table 2). PCRs were performed using TaKaRaEpiTaq ${ }^{\mathrm{TM}} \mathrm{HS}$, as recommended by the manufacturer (TAKARA BIO INC, Tokyo Japan). The amplicons were resolved on agarose gels, purified using the QIAquick Gel Extraction Kit gel-extraction kit (Qiagen, Hilden) and sequenced (Supplementary Table 2).

\section{Plasmids}

A -3029 bp fragment $(-2832 /+197)$ of the 5 '-flanking end of the FRK gene was generated from human genomic DNA by PCR using the primers listed in Supplementary Table 3. The deletions were generated from the FRK plasmid using primers listed in Supplementary Tables 3 and 4. All the fragments were cloned into the pGL3basic plasmid (Promega Corporation). Site-directed mutations were introduced in the $F R K$ promoter construct $-2832 /+197$ bp using the QuikChange II XL mutagenesis kit (Stratagene, La Jolla, CA) and oligonucleotides listed in Supplementary Table 5. Plasmids were verified by sequencing (National Research Council Canada, Saskatoon, SK). The wild type and constitutively active STAT5 expression vectors were provided by Dr. Luc J Martin, University of Moncton, Moncton NB [66].

\section{Transfections and luciferase assays}

Transfections of AU565 and HCC70 cells were performed in 24-well plates using the ViaFect $^{(\mathrm{TM})}$ as recommended by the vendor (Promega Corporation). Briefly, on the day before transfection, 125,000 cells were seeded with $500 \mu \mathrm{L}$ of media per well in 24 -well plates. Cells were then transfected with $500 \mathrm{ng}$ per well: $495 \mathrm{ng}$ of FRK-reporter construct (Firefly Luciferase) along with 5 ng of phRL-TK (Renilla Luciferase) as an internal control for transfection efficiency. The cells were harvested 40 hours post-transfection and the Dual-Luciferase Assay System used to measure luciferase activities with the GloMax ${ }^{\circledR} 96$ Microplate Luminometer (Promega Corporation). Data reported represents an average of at least three experiments. To evaluate the role of the effectors on the FRK promoter, cells were co-transfected with $250 \mathrm{ng}$ of either the effector plasmid or an empty pCDNA3 vector with $245 \mathrm{ng}$ the $F R K$ reporters and $5 \mathrm{ng}$ phRL-TK internal control per well (Invitrogen Canada).

\section{Statistical analysis}

The data was analyzed by a one-way analysis of variance (ANOVA; SigmaStat Version 2.0, Jadel Corporation, San Rafael, CA, USA). Multiple range comparisons of paired means were done using a Fishers LSD test or the Newman-Keuls test. Level of significance was set at $P<0.05$. Data is reported as mean \pm SEM.

\section{Abbreviations}

Please see Supplementary Table 7 for list of acronyms.

\section{ACKNOWLEDGMENTS}

We thank Dr. Deborah Anderson of the Saskatchewan Cancer Agency for providing us withbreast cancer cells.

\section{CONFLICTS OF INTEREST}

No conflicts of interest that might be perceived as affecting the objectivity of this article.

\section{FUNDING}

This work was supported by grants from the Saskatchewan Cancer Agency and Prairie/NWT Region Canadian Breast Cancer Foundation (KB and KEL). The trainees, SM, CD, TS, and RKG, were funded by the trainee grant CIHR (KEL) while EB and MS were beneficiaries of graduate fellowships from the University of Saskatchewan.

\section{Authors' contributions}

ETB performed most of the experiments and analyzed the data, SM performed immunoblotting experiments and analysis. CD assisted ETB in bisulphite sequencing. TS assisted ETB in cloning and site-directed mutagenesis. YO assisted ETB in performing DAC treatment. EB carried out some of the RT-PCR experiments. MS performed some of the HDI treatments. RKG reviewed some sections of the manuscript. ETB KB and KEL conceived and designed the experiments and wrote the manuscript. KB and KEL provided supervision. Please see Supplementary Table 7 for list of acronyms

\section{REFERENCES}

1. Ferlay J, Soerjomataram I, Dikshit R, Eser S, Mathers C, Rebelo M, Parkin DM, Forman D, Bray F. Cancer incidence and mortality worldwide: sources, methods and major patterns in GLOBOCAN 2012. Int J Cancer. 2015; 136: E359-86. doi: 10.1002/ijc.29210.

2. Carey L, Winer E, Viale G, Cameron D, Gianni L. Triple-negative breast cancer: disease entity or title of convenience? Nature reviews Clinical oncology. 2010; 7: 683-92. doi: 10.1038/nrclinonc.2010.154.

3. Kao J, Salari K, Bocanegra M, Choi YL, Girard L, Gandhi J, Kwei KA, Hernandez-Boussard T, Wang P, Gazdar AF, Minna JD, Pollack JR. Molecular profiling of breast cancer cell lines defines relevant tumor models and provides a 
resource for cancer gene discovery. PLoS One. 2009; 4: e6146. doi: 10.1371/journal.pone.0006146.

4. Holliday DL, Speirs V. Choosing the right cell line for breast cancer research. Breast Cancer Res. 2011; 13:215. doi: 10.1186/bcr2889.

5. Sheng ZM, Marchetti A, Buttitta F, Champeme MH, Campani D, Bistocchi M, Lidereau R, Callahan R. Multiple regions of chromosome $6 \mathrm{q}$ affected by loss of heterozygosity in primary human breast carcinomas. Br J Cancer. 1996; 73: 144-7.

6. Chandrasekharan S, Qiu TH, Alkharouf N, Brantley K, Mitchell JB, Liu ET. Characterization of mice deficient in the Src family nonreceptor tyrosine kinase Frk/rak. Mol Cell Biol. 2002; 22: 5235-47.

7. Goel RK, Lukong KE. Tracing the footprints of the breast cancer oncogene BRK - Past till present. Biochim Biophys Acta. 2015; 1856:39-54. doi: 10.1016/j.bbcan.2015.05.001.

8. Serfas MS, Tyner AL. Brk, Srm, Frk, and Src42A form a distinct family of intracellular Src-like tyrosine kinases. Oncol Res. 2003; 13: 409-19.

9. Cance WG, Craven RJ, Bergman M, Xu L, Alitalo K, Liu ET. Rak, a novel nuclear tyrosine kinase expressed in epithelial cells. Cell Growth Differ. 1994; 5:1347-55.

10. Oberg-Welsh C, Anneren C, Welsh M. Mutation of C-terminal tyrosine residues Y497/Y504 of the Src-family member Bsk/Iyk decreases NIH3T3 cell proliferation. Growth Factors. 1998; 16: 111-24.

11. Anneren C, Welsh M. Role of the Bsk/Iyk non-receptor tyrosine kinase for the control of growth and hormone production in RINm5F cells. Growth Factors. 2000; 17: 233-47.

12. Goel RK, Lukong KE. Understanding the cellular roles of Fyn-related kinase (FRK): implications in cancer biology. Cancer Metastasis Rev. 2016. doi: 10.1007/s10555-0169623-3.

13. Yim EK, Peng G, Dai H, Hu R, Li K, Lu Y, Mills GB, Meric-Bernstam F, Hennessy BT, Craven RJ, Lin SY. Rak functions as a tumor suppressor by regulating PTEN protein stability and function. Cancer Cell. 2009; 15:304-14. doi: S1535-610800043-9 [pii] 10.1016/j.ccr.2009.02.012.

14. Yim EK, Siwko S, Lin SY. Exploring Rak tyrosine kinase function in breast cancer. Cell Cycle. 2009; 8:2360-4. doi: 9264 [pii].

15. Brauer PM, Tyner AL. RAKing in AKT: a tumor suppressor function for the intracellular tyrosine kinase FRK. Cell Cycle. 2009; 8:2728-32. doi: 9389 [pii].

16. Shi Q, Song X, Wang J, Gu J, Zhang W, Hu J, Zhou X, $\mathrm{Yu}$ R. FRK inhibits migration and invasion of human glioma cells by promoting N-cadherin/beta-catenin complex formation. J Mol Neurosci. 2015; 55:32-41. doi: 10.1007/ s12031-014-0355-y.

17. Goel RK, Lukong KE. Understanding the cellular roles of Fyn-related kinase (FRK): implications in cancer biology. Cancer Metastasis Rev. 2016; 35:179-99. doi: 10.1007/ s10555-016-9623-3.
18. Craven RJ, Cance WG, Liu ET. The nuclear tyrosine kinase Rak associates with the retinoblastoma protein $\mathrm{pRb}$. Cancer research. 1995; 55:3969-72.

19. Hua L, Zhu M, Song X, Wang J, Fang Z, Zhang C, Shi Q, Zhan W, Wang L, Meng Q, Zhou X, Yu R. FRK suppresses the proliferation of human glioma cells by inhibiting cyclin D1 nuclear accumulation. J Neurooncol. 2014; 119:49-58. doi: 10.1007/s11060-014-1461-y.

20. Craven RJ, Cance WG, Liu ET. The nuclear tyrosine kinase Rak associates with the retinoblastoma protein $\mathrm{pRb}$. Cancer Res. 1995; 55: 3969-72.

21. Berclaz G, Altermatt HJ, Rohrbach V, Dreher E, Ziemiecki A, Andres AC. Hormone-dependent nuclear localization of the tyrosine kinase iyk in the normal human breast epithelium and loss of expression during carcinogenesis. Int J Cancer. 2000; 85:889-94.

22. Kim JL, Ha GH, Campo L, Denning MF, Patel TB, Osipo C, Lin SY, Breuer EK. The role of Rak in the regulation of stability and function of BRCA1. Oncotarget. 2015 Oct 14. doi: 10.18632/oncotarget.5717. [Epub ahead of print].

23. Pajer P, Karafiat V, Pecenka V, Prukova D, Dudlova J, Plachy J, Kasparova P, Dvorak M. Industasis, a promotion of tumor formation by nontumorigenic stray cells. Cancer Res. 2009; 69:4605-12. doi: 10.1158/0008-5472.CAN08-4636.

24. Connolly R, Stearns V. Epigenetics as a therapeutic target in breast cancer. J Mammary Gland Biol Neoplasia. 2012; 17: 191-204. doi: 10.1007/s10911-012-9263-3.

25. Lustberg MB, Ramaswamy B. Epigenetic targeting in breast cancer: therapeutic impact and future direction. Drug News Perspect. 2009; 22:369-81. doi: 10.1358/ dnp.2009.22.7.1405072.

26. Jones PA, Baylin SB. The fundamental role of epigenetic events in cancer. Nature reviews Genetics. 2002; 3:415-28. doi: $10.1038 / \mathrm{nrg} 816$.

27. Kulis M, Esteller M. DNA methylation and cancer. Advances in genetics. 2010; 70: 27-56. doi: 10.1016/B9780-12-380866-0.60002-2.

28. Herman JG, Baylin SB. Gene silencing in cancer in association with promoter hypermethylation. The New England journal of medicine. 2003; 349:2042-54. doi: 10.1056/NEJMra023075.

29. Rodriguez-Paredes M, Esteller M. Cancer epigenetics reaches mainstream oncology. Nature medicine. 2011; 17 : 330-9. doi: 10.1038/nm.2305.

30. Yuan Y, Mendez R, Sahin A, Dai JL. Hypermethylation leads to silencing of the SYK gene in human breast cancer. Cancer research. 2001; 61:5558-61.

31. Berclaz G, Altermatt HJ, Rohrbach V, Dreher E, Ziemiecki A, Andres AC. Hormone-dependent nuclear localization of the tyrosine kinase iyk in the normal human breast epithelium and loss of expression during carcinogenesis. International journal of cancer Journal international du cancer. 2000; 85: 889-94. 
32. Meric F, Lee WP, Sahin A, Zhang H, Kung HJ, Hung MC. Expression profile of tyrosine kinases in breast cancer. Clin Can Res. 2002; 8: 361-7.

33. Meyer T, Xu L, Chang J, Liu ET, Craven RJ, Cance WG. Breast cancer cell line proliferation blocked by the Srcrelated Rak tyrosine kinase. Int J Cancer. 2003; 104:139-46. doi: 10.1002/ijc.10925.

34. Jin L, Craven RJ. The Rak/Frk tyrosine kinase associates with and internalizes the epidermal growth factor receptor. Oncogene. 2014; 33:326-35. doi: 10.1038/onc.2012.589.

35. Devereux TR, Horikawa I, Anna CH, Annab LA, Afshari CA, Barrett JC. DNA methylation analysis of the promoter region of the human telomerase reverse transcriptase (hTERT) gene. Cancer Res. 1999; 59:6087-90.

36. Moarii M, Boeva V, Vert JP, Reyal F. Changes in correlation between promoter methylation and gene expression in cancer. Bmc Genomics. 2015; 16. doi: ARTN 87310.1186/ s12864-015-1994-2.

37. Yan WJ, Wu KM, Herman JG, Brock MV, Zhou YS, Lu YY, Zhang ZQ, Yang YS, Guo MZ. Epigenetic silencing of DACH1 induces the invasion and metastasis of gastric cancer by activating TGF-beta signalling. Journal of Cellular and Molecular Medicine. 2014; 18:2499-511. doi: 10.1111/jcmm.12325.

38. Momparler RL. Pharmacology of 5-Aza-2'-deoxycytidine (decitabine). Semin Hematol. 2005; 42:S9-16.

39. Wu LP, Wang X, Li L, Zhao Y, Lu SL, Yu Y, Zhou W, Liu XY, Yang J, Zheng ZX, Zhang H, Feng JN, Yang Y, et al. Histone deacetylase inhibitor depsipeptide activates silenced genes through decreasing both $\mathrm{CpG}$ and $\mathrm{H} 3 \mathrm{~K} 9$ methylation on the promoter. Molecular and Cellular Biology. 2008; 28:3219-35. doi: 10.1128/Mcb.01516-07.

40. Sarkar S, Abujamra AL, Loew JE, Forman LW, Perrine SP, Faller DV. Histone Deacetylase Inhibitors Reverse CpG Methylation by Regulating DNMT1 through ERK Signaling. Anticancer Research. 2011; 31:2723-32.

41. Choi JH, Min NY, Park J, Kim JH, Park SH, Ko YJ, Kang Y, Moon YJ, Rhee S, Ham SW, Park AJ, Lee KH. TSA-induced DNMT1 down-regulation represses hTERT expression via recruiting CTCF into demethylated core promoter region of hTERT in HCT116. Biochem Biophys Res Commun. 2010; 391:449-54. doi: 10.1016/j.bbrc.2009.11.078.

42. Ehret GB, Reichenbach P, Schindler U, Horvath CM, Fritz S, Nabholz M, Bucher P. DNA binding specificity of different STAT proteins. Comparison of in vitro specificity with natural target sites. J Biol Chem. 2001; 276:6675-88. doi: 10.1074/jbc.M001748200.

43. Soldaini E, John S, Moro S, Bollenbacher J, Schindler U, Leonard WJ. DNA binding site selection of dimeric and tetrameric Stat5 proteins reveals a large repertoire of divergent tetrameric Stat5a binding sites. Mol Cell Biol. 2000; 20:389-401.

44. Merika M, Orkin SH. DNA-binding specificity of GATA family transcription factors. Mol Cell Biol. 1993; 13: 3999-4010.
45. Rabinovich A, Jin VX, Rabinovich R, Xu X, Farnham PJ. E2F in vivo binding specificity: comparison of consensus versus nonconsensus binding sites. Genome Res. 2008; 18 : 1763-77. doi: 10.1101/gr.080622.108.

46. Bagu ET, Layoun A, Calve A, Santos MM. Friend of GATA and GATA- 6 modulate the transcriptional up-regulation of hepcidin in hepatocytes during inflammation. Biometals. 2013; 26:1051-65. doi: 10.1007/s10534-013-9683-6.

47. Robert NM, Tremblay JJ, Viger RS. Friend of GATA (FOG)-1 and FOG-2 differentially repress the GATA-dependent activity of multiple gonadal promoters. Endocrinology. 2002; 143: 3963-73. doi: 10.1210/en.2002-220280.

48. Esteller M. CpG island hypermethylation and tumor suppressor genes: a booming present, a brighter future. Oncogene. 2002; 21:5427-40. doi: 10.1038/sj.onc.1205600.

49. Huang WY, Hsu SD, Huang HY, Sun YM, Chou CH, Weng SL, Huang HD. MethHC: a database of DNA methylation and gene expression in human cancer. Nucleic Acids Res. 2015; 43:D856-61. doi: 10.1093/nar/gku1151.

50. Choi JH, Park SH, Park J, Park BG, Cha SJ, Kong KH, Lee KH, Park AJ. Site-specific methylation of $\mathrm{CpG}$ nucleotides in the hTERT promoter region can control the expression of hTERT during malignant progression of colorectal carcinoma. Biochemical and Biophysical Research Communications. 2007; 361:615-20. doi: 10.1016/j. bbrc.2007.07.051.

51. Momparler RL. Epigenetic therapy of cancer with 5-aza2'-deoxycytidine (decitabine). Seminars in Oncology. 2005; 32:443-51. doi: 10.1053/j.seminoncol.2005.07.008.

52. Marks PA. Histone deacetylase inhibitors: a chemical genetics approach to understanding cellular functions. Biochim Biophys Acta. 2010; 1799:717-25. doi: 10.1016/j. bbagrm.2010.05.008.

53. Ceccacci E, Minucci S. Inhibition of histone deacetylases in cancer therapy: lessons from leukaemia. Br J Cancer. 2016; 114:605-11. doi: 10.1038/bjc.2016.36.

54. Fraczek J, Vanhaecke T, Rogiers V. Toxicological and metabolic considerations for histone deacetylase inhibitors. Expert Opin Drug Metab Toxicol. 2013; 9:441-57. doi: 10.1517/17425255.2013.754011.

55. Bovenzi V, Momparler RL. Antineoplastic action of 5-aza2'-deoxycytidine and histone deacetylase inhibitor and their effect on the expression of retinoic acid receptor beta and estrogen receptor alpha genes in breast carcinoma cells. Cancer Chemother Pharmacol. 2001; 48:71-6.

56. Christman JK. 5-Azacytidine and 5-aza-2 '-deoxycytidine as inhibitors of DNA methylation: mechanistic studies and their implications for cancer therapy. Oncogene. 2002; 21: 5483-95. doi: 10.1038/sj.onc.1205699.

57. Schmelz K, Wagner M, Dorken B, Tamm I. 5-Aza-2'deoxycytidine induces p21WAF expression by demethylation of p73 leading to $\mathrm{p} 53$-independent apoptosis in myeloid leukemia. Int J Cancer. 2005; 114:683-95. doi: 10.1002/ijc.20797. 
58. Zhu WG, Dai ZY, Ding HM, Srinivasan K, Hall J, Duan WR, Villalona-Calero MA, Plass C, Otterson GA. Increased expression of unmethylated CDKN2D by 5-aza2'-deoxycytidine in human lung cancer cells. Oncogene. 2001; 20: 7787-96. doi: DOI 10.1038/sj.onc. 1204970.

59. Saito A, Yamashita T, Mariko Y, Nosaka Y, Tsuchiya K, Ando T, Suzuki T, Tsuruo T, Nakanishi O. A synthetic inhibitor of histone deacetylase, MS-27-275, with marked in vivo antitumor activity against human tumors. Proc Natl Acad Sci USA. 1999; 96: 4592-7.

60. Vettese-Dadey M, Grant PA, Hebbes TR, CraneRobinson C, Allis CD, Workman JL. Acetylation of histone $\mathrm{H} 4$ plays a primary role in enhancing transcription factor binding to nucleosomal DNA in vitro. EMBO J. 1996; 15: 2508-18.

61. Vanselow J, Yang W, Herrmann J, Zerbe H, Schuberth HJ, Petzl W, Tomek W, Seyfert HM. DNA-remethylation around a STAT5-binding enhancer in the alphaS1-casein promoter is associated with abrupt shutdown of alphaS1casein synthesis during acute mastitis. J Mol Endocrinol. 2006; 37:463-77. doi: 10.1677/jme.1.02131.

62. Cantor AB, Orkin SH. Coregulation of GATA factors by the Friend of GATA (FOG) family of multitype zinc finger proteins. Semin Cell Dev Biol. 2005; 16:117-28. doi: 10.1016/j.semcdb.2004.10.006.
63. Franceschini A, Szklarczyk D, Frankild S, Kuhn M, Simonovic M, Roth A, Lin J, Minguez P, Bork P, von Mering C, Jensen LJ. STRING v9.1: protein-protein interaction networks, with increased coverage and integration. Nucleic Acids Res. 2013; 41:D808-15. doi: 10.1093/nar/gks1094.

64. Miah S, Goel RK, Dai C, Kalra N, Beaton-Brown E, Bagu ET, Bonham K, Lukong KE. BRK Targets Dok1 for Ubiquitin-Mediated Proteasomal Degradation to Promote Cell Proliferation and Migration. PLoS One. 2014; 9:e87684. doi: 10.1371/journal.pone.0087684.

65. Li LC, Dahiya R. MethPrimer: designing primers for methylation PCRs. Bioinformatics. 2002; 18:1427-31. doi: DOI 10.1093/bioinformatics/18.11.1427.

66. Onishi M, Nosaka T, Misawa K, Mui ALF, Gorman D, McMahon M, Miyajima A, Kitamura T. Identification and characterization of a constitutively active STAT5 mutant that promotes cell proliferation. Molecular and Cellular Biology. 1998; 18:3871-9. 